\title{
Mathematical Modeling of Production and Biorefinery of Energy Crops
}

\author{
Lijun Wang $^{1 *}$ and Samuel A. Agyemang ${ }^{2}$, Hossein Amini ${ }^{2}$ and Abolghasem Shahbazi ${ }^{1}$ \\ ${ }^{1}$ Biological Engineering Program, Department of Natural Resources and Environmental Design \\ ${ }^{2}$ Department of Computational Science and Engineering
}

North Carolina Agricultural and Technical State University, 1601 E. Market Street, Greensboro, NC27411

\begin{abstract}
Mathematical models have been widely used to simulate all aspects of bioenergy production systems including the growth kinetics of energy crops, conversion processes, production economics, supply logistics and environmental impacts. There is limited commercial experience to produce and process energy crops at a large scale around the world. Those models can provide powerful tools to design a bioenergy system and evaluate its technical feasibility, economics and environmental impacts. A crop growth model can be used to estimate the yields of energy crops in a region under different growth conditions. A geographical information system (GIS) model can be used to maximize the energy production of energy crops by indentifying suitable land to grow them based on their specific characteristics and the current use of the land. A combination of process models and reaction kinetics provides advanced computational tools for the design

\footnotetext{
* Corresponding author, Tel: +1 336 2853833, Fax: +1 336 3347270, Email: lwang@ncat.edu (L.J. Wang)
} 
and optimization of various biomass conversion processes. The biomass supply chain consists of multiple harvesting, storage, pre-processing and transport options. Mathematical models have been developed to analyze and optimize complex biomass supply systems. A life cycle assessment (LCA) model can be used to compare the environmental impacts of different biomass production and conversion technologies. Various mathematical models applied to bioenergy systems were reviewed. The challenges in mathematical modeling of bioenergy systems which include the difficulty in generalizing a bioenergy system, the lack of physical and chemical properties of various biomass, the complexity of multi-scale processes and the validation of the models were then discussed.

Keywords: crop growth kinetics; biorefinery; mathematical modeling; computational fluid dynamics; life cycle assessment; geographical information system; biomass supply logistics.

\section{Content}

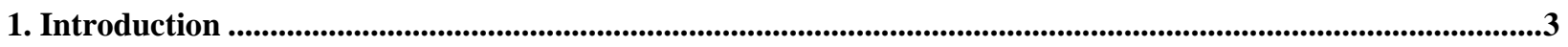

2. Mathematical Modeling of the Production of Energy Crops..........................................................................................4

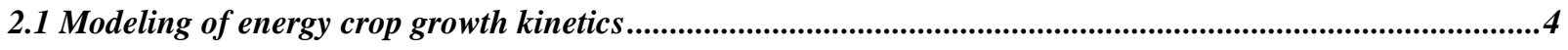

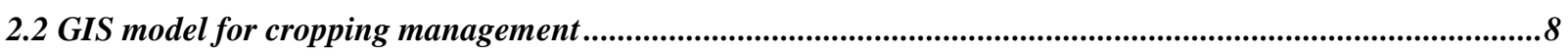

3. Computer Aided Biofinery Design and Analysis ......................................................................................................

3.1 Biomass conversion kinetics.................................................................................................................................

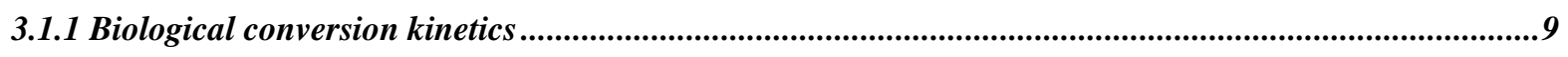

3.1.2 Thermochemical conversion kinetics .............................................................................................................12

3.2 Mathematical Modeling of Transportation Phenomena in a Biorefinery ......................................................14

3.2.1 CFD modeling of multiphase flows in bioenergy processing ....................................................................14 


\section{Introduction}

Lignocellulosic biomass is an abundant renewable energy source. Energy crops such as switchgrass, sweet sorghum and microalgae have been widely investigated to fulfill the future energy and chemical demands. Biorefineries which integrate different conversion processes including thermochemical, chemical and biological conversion are required to convert various biomass feedstocks into different energy products such as alcohols, biodiesels, syngas and 
hydrogen. A bioenergy system involves the interaction between chemical and physical processes at a multi-scale of molecular, reactor and system levels. A bioenergy supply chain typically has five major components of biomass production, biomass logistics, biomass-to-product conversion, product distribution and product end use [1].

There are few commercial bioenergy systems in operation. The design and analysis of a bioenergy system is challenging due to the complexity of the system, and the lack of data and knowledge. Experiments at a large scale are often expensive and complicated. Mathematical models can provide economical and powerful tools for the design and optimization of a bioenergy system. There are four basic groups of mathematical modeling techniques applied in bioenergy systems: (1) biomass production models [2], (2) biorefinery processing models [3], (3) economic models of bioenergy supply chains [4, 5], and (4) life cycle assessment models of bioenergy systems $[6,7]$.

This article was to review the various mathematical models that have been developed to simulate bioenergy systems including production of energy crops, conversion of biomass into different energy products, biomass supply logistics and environmental impacts of a bioenergy system. The challenges in mathematical modeling of bioenergy systems were then discussed.

\section{Mathematical Modeling of the Production of Energy Crops}

\subsection{Modeling of energy crop growth kinetics}

Energy crops such as switchgrass, sweet sorghum and microalgae have been widely investigated. However, there is limited commercial experience to produce energy crops at a large scale around 
the world [2]. The yield of energy crops is an important parameter to assess their production cost. A crop growth model can be used to estimate the yields of energy crops in a region under different situations. Van den Broek et al. (2001) developed an energy crop growth model to estimate potential and water-limited yields for a certain region on the basis of solar radiation and daily data for precipitation and pan-evaporation. The potential growth rate of an energy crop at a specific region where temperature, fertilizers and water are not limiting growth factors was calculated by [2]:

$G_{p}=\varepsilon \varphi f_{P A R}\left(1-e^{-k \cdot L A I}\right) H I$

where $G_{p}$ is the potential rate $\left(g_{d m} / m^{2}\right.$ day), $\varepsilon$ is the crop radiation utilization coefficient $\left(\mathrm{g}_{\mathrm{dm}} / \mathrm{MJ}_{\mathrm{PAR}}\right), \varphi$ is the solar radiation $\left(\mathrm{MJ} / \mathrm{m}^{2}\right.$ day $), \mathrm{f}_{\mathrm{PAR}}$ is the amount of photo-synthetically active radiation (-), LAI is the leaf area index $\left(m_{\text {leaf }}^{2} / m_{\text {ground }}^{2}\right), \mathrm{k}$ is the canopy extinction coefficient $\left(m_{\text {ground }}^{2} / m_{\text {leaf }}^{2}\right)$ and HI is the harvest index (-). The input data for the growth of Eucalyptus camaldulensis in Nicaragua are given in Table 1 [2].

The temperature, nitrogen and water-limited growth rate can further be calculated as a function of the potential growth rate by taking into account of individual limiting factors, which was given by $[2,8]$ :

$G_{l}=f_{T} f_{N} f_{W} G_{p}$

where $f_{T}, f_{N}$ and $f_{W}$ are limiting factors for temperature, nitrogen availability and water in the soil. The limiting factors can be determined by [8]:

$$
\begin{aligned}
& f_{T}=\left(T-T_{\min }\right) /\left(T_{\max }-T_{\min }\right) \\
& f_{N}=\left(N_{\text {leaf }}-N_{\text {leaf }, \text { min }}\right) /\left(N_{\text {leaf }, \text { max }}-N_{\text {leaf }, \text { min }}\right)
\end{aligned}
$$




$$
f_{W}=E_{t} / E_{t p}
$$

where $\mathrm{T}$ is temperature, $\mathrm{N}$ is nitrogen, $\mathrm{E}_{\mathrm{t}}$ is the actual transpiration in the soil and $\mathrm{E}_{\mathrm{tp}}$ is the potential transpiration in the soil.

The use of a crop growth model requires input data such as meteorological data, soil data, and crop characteristics, which can be determined at a reference location. However, the interactions between site-specific properties such as climate, available soil water and nutrients and crop growth are complex. Therefore, the above model assumes that the nutrient conditions and yield reduction by weeds, pests and diseases at a specific location and reference location are the same [2]. The predictions showed that the potential and water-limited yields for the growth of Eucalyptus camaldulensis in Nicaragua, the Netherland were 35 ton dry mass /(ha year) and 23 ton dry mass /(ha year), respectively. The actual yield was 13 ton dry mass /(ha year), which was about $58 \%$ of its water-limited yield [2].

\begin{abstract}
Algae are another attractive energy crop because they do not compete with food crops and have higher yields per unit of area than terrestrial energy crops such as switchgrass. Small algae can achieve higher rates of photosynthesis and specific growth rate, and faster uptake of nutrients per unit mass of biomass [9]. Therefore, since algae at different sizes present in the cultivation system, it cannot be assumed that all cells have the same growth rate in a mathematical model for the simulation of algal growth. Concas et al. (2010) developed a mass-dependent growth kinetics model, which also considered the effects of light intensity, nutrients concentration and inhibitors of dissolved oxygen on the microalgae growth kinetics [10]. The changing rate of cell mass was given by [10]
\end{abstract}


$d m / d t=\left\{\mu_{\max }\left[I^{n} /\left(I_{K}^{n}+I^{n}\right)\right] \times \prod_{j=1}^{2}\left[C_{j} /\left(K_{j}+C_{j}\right)\right]\left(1-C_{O_{2}} / C_{O_{2}, \max }\right)\right\} m$

where $\mathrm{m}$ is the single cell mass $(\mathrm{g}), \mu_{\max }$ is the maximum specific rate of cell growth $\left(\mathrm{s}^{-1}\right), \mathrm{I}$ is the photosynthetically active radiation within the culture $\left(\mu \mathrm{E} \mathrm{m}^{-2} \mathrm{~s}^{-1}\right), \mathrm{I}_{\mathrm{K}}$ is half saturation constant for photosynthetically active radiation $\left(\mu \mathrm{E} \mathrm{m}^{-2} \mathrm{~s}^{-1}\right), \mathrm{n}$ is the coefficient appearing in the rate of cell growth, $K_{j}$ is half saturation constant of $j^{\text {th }}$ nutrient $\left(\mathrm{g} \mathrm{m}^{-3}\right), C_{j}$ is concentration of $j^{\text {th }}$ nutrient in culture medium $\left(\mathrm{g} \mathrm{m}^{-3}\right), \mathrm{C}_{\mathrm{O}_{2}}$ is the dissolved oxygen concentration in culture medium $\left(\mathrm{g} \mathrm{m}^{-3}\right)$, $\mathrm{C}_{\mathrm{O}_{2}, \max }$ is the dissolved oxygen concentration at which algal growth is inhibited $\left(\mathrm{g} \mathrm{m}^{-3}\right)$, and $\mu_{\mathrm{c}}$ is catabolic growth rate $\left(\mathrm{s}^{-1}\right)$.

The death of mother cell and the cell birth due to mitosis can be determined by probability partition function [10]. Every microalgal species has optimal requirements of light intensity, nutrients and $\mathrm{CO}_{2}$, temperature and $\mathrm{pH}$ value. Concas et al. (2010) collected the model parameters for Spirulina platensis from literature, which is given in Table 2 [10].

One of the main research efforts in the area of microalgal cultivation is to identify algal strains with high lipid content for the production of biodiesel and jet fuels. Many green microalgae can increase their cellular neutral lipid content when cultured in nitrogen limited or high light conditions. A mathematical model can be used to predict the lipid production of microalgae with respect to nutrient and light conditions [11]. Four ordinary differential equations as given below were developed to describe (1) the algal growth or the time-dependent algal biomass concentration excluding neutral lipids, $\mathrm{A}(\mathrm{t})\left(\mathrm{g} / \mathrm{m}^{3}\right.$, dry mass), (2) the neutral lipid concentration, $\mathrm{L}(\mathrm{t})\left(\mathrm{g} / \mathrm{m}^{3}\right)$, (3) the chl a content in biomass, $\mathrm{H}(\mathrm{t})(\mathrm{g}$ chl/g biomass, dry mass), and (4) the 
extracellular nitrogen concentration, $\mathrm{N}(\mathrm{t})\left(\mathrm{g} / \mathrm{m}^{3}\right)$. The algal mass consists of non-neutral lipid biomass A and neutral lipids L. The assumption of the model was that when the algal growth of $\mathrm{A}(\mathrm{t})$ ceases, excess carbon and energy is used to produce neutral lipids, $\mathrm{L}(\mathrm{t})$.

$$
\begin{aligned}
& d A(t) / d t=\mu(A, L, H, N) A(t) \\
& d L(t) / d t=[p(A . L . H, N)-c \mu(A, L, H, N)] A(t) \\
& d H(t) / d t=c \frac{\mu(A, L, H, N)}{p(A, L, H, N)} \rho v(A, N)-H(t) \mu(A, L, H, N) \\
& d N(t) / d t=-v(A, N) A(t)
\end{aligned}
$$

In the above equations, the coefficients, $\mu, \mathrm{p}$ and $\mathrm{v}$ were determined as functions of nitrogen and light conditions. The coefficients of $\mathrm{c}$ and $\rho$ are $\mathrm{C}$ subsistence quota and maximum chl:N, respectively. The comparison between predicted and experimental data for Pseudochlorococcum $s p$. showed that the model could predict the algal growth and neutral lipid synthesis very well for growth media with low nitrogen concentration. However, the model overestimated the biomass for the growth media with high nitrogen concentration [11].

\subsection{GIS model for cropping management}

A geographical information system (GIS) is a spatial modeling tool, which includes digital maps and tables of attributes linked to map identities. GIS can be used to combine various digital agronomic data such as the irradiation and the slope of land, and to mark the areas with the most feasible energy crop production in each layer. Digital layers are subsequently combined according to hierarchical factors of contribution to the feasible growth of the energy crops. Fig.1 shows the agroclimate variables and their contribution for the growth of energy crop of Brassica $s p$. [12]. The total potential crop area (TPCA) can be determined by adding the scores of 
individual agronomic factors, $\mathrm{AF}_{\mathrm{i}}$, multiplied by their weighting factors, $\mathrm{W}_{\mathrm{i}}$, which is given by [12]:

$T P C A=\sum A F_{i} \cdot W_{i}$

A GIS model can be used to maximize the energy production of energy crops by indentifying suitable land to grow them based on their specific characteristics and the current use of the land [13]. The integration of GIS and life cycle assessment (LCA) can provide an effective method to determine the implementation strategy to reduce energy consumption and $\mathrm{CO}_{2}$ emissions for growing energy crops at a local and decentralized scale [12].

\section{Computer Aided Biofinery Design and Analysis}

\subsection{Biomass conversion kinetics}

Biomass can be converted into energy products in various biological processes such as fermentation and anaerobic digestion, and thermochemical processes such as combustion, pyrolysis and gasification. The biological or thermochemical conversion of biomass involves reactions. A reaction kinetic model describes how the reaction rate depends on the key local environmental variables such as temperature and pressure. Both empirical and mechanistic equations were developed to describe the kinetics of reactions.

\subsubsection{Biological conversion kinetics}

The microbial growth profiles include linear, exponential, logistic and fast-acceleration/slow deceleration as shown in Fig.2. Empirical equations can be used to simply fit experimental data of microbial growth by non-linear regression. The following equations have been developed to 
describe these curves for solid-state fermentation as shown in Fig.2 [14]:

Linear: $d X / d t=K$ or $X=K t+X_{0}$

Exponential: $d X / d t=\mu X$ or $X=X_{0} e^{\mu t}$

Logistic: $d X / d t=\mu X\left(1-X / X_{m}\right)$ or $X=X_{m} /\left[1+\left(X_{m} / X_{0}-1\right) e^{\mu t}\right]$

Two phase: $d X / d t=\mu X,\left(t<t_{a}\right)$ or $X=X_{0} e^{\mu t}$

$d X / d t=\left[\mu L e^{-k\left(t-t_{a}\right)}\right] X,\left(t \geq t_{a}\right)$ or $X=X_{A} \exp \left[(\mu L / k)\left(1-e^{-k\left(t-t_{a}\right)}\right)\right]$

where $\mathrm{K}$ is the reaction constant, $\mu$ is the specific growth rate, $\mathrm{X}$ is the biomass concentration, $\mathrm{X}_{\mathrm{m}}$ is the maximum possible biomass concentration, $\mathrm{t}_{\mathrm{a}}$ is the time that the exponential is switched to deceleration phase, $\mathrm{L}$ is the ratio of the specific growth rate at the start of the deceleration phase to the specific growth rate during the exponential phase.

The modified Gompertz equation is another kinetic model to fit the experimental data of cell growth and product formation curves in order to estimate the maximum specific growth/production rates, lag phase and maximum cell/product concentration. The modified Gompertz equation is given by $[15,16]$ :

$\left.\log \left(X / X_{0}\right)=A \cdot \exp \left\{-\exp \mid\left(\mu_{\max } \cdot e / A\right)\left(t_{\text {lag }}-t\right)+1\right\}\right\}$

where $\mu_{\max }$ is the maximum specific growth/production rate, $\mathrm{A}$ is potential maximum cell or production concentration, $\mathrm{t}_{\mathrm{lag}}$ is the delayed time, and $\mathrm{X}$ and $\mathrm{X}_{0}$ are the cell concentration at any time $t$ and at the beginning.

During biological conversion, the substrate and product may have significant inhibition on the maximum specific growth rate and maximum ethanol production rate [17]. The modified Monod 
kinetic model is the most widely used empirical model to describe the microbial growth under the inhibition of substrate and product, which is given by [18]:

$d X / d t=\mu X=\mu_{\max }\left[S /\left(S+K_{S}+S^{2} / K_{I}\right)\right]\left(1-P / P_{d}\right)^{n} X$

In the above equation, $\mathrm{K}_{\mathrm{S}}$ and $\mathrm{K}_{\mathrm{I}}$ are the substrate saturation and inhibition constants $(\mathrm{g} / \mathrm{L})$, respectively, $\mathrm{P}$ is the product concentration $(\mathrm{g} / \mathrm{L}), \mathrm{P}_{\mathrm{d}}$ is the product concentration at which no cell growth occurs $(\mathrm{g} / \mathrm{L})$, and $\mathrm{n}$ is the degree of product inhibition.

The effect of temperature on the microbial growth kinetics can be determined by the modified Ratkowsky model, which is expressed as $[15,19]$ :

$\mu_{\max }=\left[\alpha\left(T-T_{\min }\right)\right]^{2} \cdot\left\{1-\exp \left[\beta\left(T-T_{\max }\right)\right]\right\}$

where $\alpha$ and $\beta$ are constants, $T_{\min }$ and $T_{\max }$ are the minimum and maximum temperatures.

The production rate may or may not be associated with the growth rate of a microorganism used in a biological process. The relationship between the production rate and the cellular growth rate can be generally expressed as $[18 ; 20]$ :

$d P / d t=\alpha(d X / d t)+\beta X$

where $\alpha, g / g$ and $\beta, g /(g h)$, are the growth-associated and non-growth-associated constants, respectively, $\mathrm{P}$ and $\mathrm{X}$ are the product and cell concentrations, respectively.

The coefficients in the kinetic models discussed above can be obtained by fitting experimental data of cell concentration-time profiles and product concentration-time profiles obtained at different process conditions such as temperature and nutrients using non-linear regression 
analysis, which can be done using the Microsoft Excel solver. The predictions using both models showed good agreement with the experimental data $[16,18]$.

\subsubsection{Thermochemical conversion kinetics}

A review on the biomass pyrolysis was given in literature [21]. A single global reaction is the simplest way to represent the whole pyrolysis reaction, which is usually treated as first-order reaction by [21]:

biomass $\stackrel{k}{\longrightarrow} \alpha \cdot$ volatiles $+(1-\alpha) \cdot$ char

where $\alpha$ is the coefficient of distribution between volatiles and char to be determined by experiments, and $\mathrm{k}$ is the reaction kinetic constant.

$d Y / d t=-k Y$

The effect of temperature on the kinetic constant is usually assumed to follow the Arrhenius law, which is given by [22]:

$k=A \exp (-E / R T)$

Experiments can be conducted with fine biomass particles to determine the constants in a kinetic model because of uniform temperature and negligible mass and heat transfer resistance through the particle. Measurements can be taken in a thermal gravimetric analyzer (TGA) with low heating rates or in a flash pyrolysis device where the heat rates are very high $\left(\right.$ e.g., $\left.500^{\circ} \mathrm{C} / \mathrm{s}\right)[23]$.

The tar cracking is considered to follow the overall reaction as [24]:

Volatile $\stackrel{k}{\longrightarrow} a_{1} \mathrm{CO}+a_{2} \mathrm{CO}_{2}+a_{3} \mathrm{H}_{2}+a_{4} \mathrm{CH}_{4}+a_{5} \mathrm{Tar}$

The stoichiometric coefficients, $\mathrm{a}_{1-5}$ and kinetics constant, $\mathrm{k}$ can be found in the literature [25, 26]. The simple pyrolysis models can only predict the amounts of char, tar and gas released 
during pyrolysis. However, they cannot predict the composition of the gas.

The improvement on the above pyrolysis kinetic model is to use a combination of series and parallel reactions as shown in Fig.3. Structural models such as Bio-FLASHCHAIN model can be used to predict the yields of individual gas [27]. In the Bio-FLASHCAHIN model, pyrolysis consists of three independent mechanisms: competitive chemical reactions, fragmentation statistics and flash distillation. Fragmentation statistics determine the probability that a specific chemical reaction will release a product with a certain molecular mass during the transformation. Flash distillation determines whether a particular fragment will enter vapor phase or remain in char in a condensed phase. All three mechanisms determine the release rates of a gaseous species [27]. Ranzi et al. (2008) proposed a mechanistic kinetic model that treated the overall devolatilization of biomass as the combination of the decomposition of the three constituent components of cellulose, hemicelluloses and lignin [28]. All the released species in the gas phase are then described with their primary propagation and decomposition reactions in the gas phase to predict the final products of $\mathrm{H}_{2}, \mathrm{CO}, \mathrm{CO}_{2}, \mathrm{CH}_{4}, \mathrm{C}_{2}$ and $\mathrm{H}_{2} \mathrm{O}$. The lumped kinetic models for the pyrolysis of cellulose, hemicelluloses and lignin were given in Table 3 [28]. The main assumption for the mechanistic kinetic model is that there are no interactions in the thermal decomposition of the three individual constituent components in a biomass feedstock. This assumption may not be right for the pyrolysis of woody biomass. The mechanistic kinetic model can be improved by accurately measuring the volatile species using FTIR and TGA-MS analyses.

During gasification, the char generated continues to react with gases of $\mathrm{O}_{2}, \mathrm{H}_{2} \mathrm{O}, \mathrm{CO}_{2}$ and $\mathrm{H}_{2}$. 
The reactivity of char can be determined as a function of the concentration of the reactant gas, $\mathrm{C}_{\mathrm{g}}$, which is given by

$r_{m}=-\left(1 / m_{c}\right)\left(d m_{c} / d t\right)=k_{m} C_{g}^{n}(\mathrm{~kg} / \mathrm{kg} \mathrm{s})$

The kinetic constant $\mathrm{k}_{\mathrm{m}}$ and the order of the reaction, $\mathrm{n}$, can be determined by experiments. The effect of temperature on the kinetic constant $\mathrm{k}_{\mathrm{m}}$ can be determined by the Arrhenius law as shown in Eq. 22 [29]. The heterogonous char-gas phase reactions and their kinetics are given in Table 4. The homogenous reactions among the gases generated during biomass gasification also take place. The homogenous gas-phase reactions and kinetics during biomass gasification are given in Table 5.

\subsection{Mathematical Modeling of Transportation Phenomena in a Biorefinery}

Although computational fluid dynamics (CFD) has been applied to industries such as aerospace, automotive and nuclear for several decades, it has only recently been applied to the bioenergy industry due to the rapid development in computer and commercial software packages [30]. Example applications of CFD in the bioenergy industry are CFD modeling of phtotobioreactors for microalgae production [31], CFD modeling of fluidized bed gasification of biomass [3], and CFD modeling of anaerobic digesters for the production of biogas from biomass [30].

\subsubsection{CFD modeling of multiphase flows in bioenergy processing}

Computational fluid dynamics (CFD) is a powerful tool used to study fluid flows and associated mass and heat transfer. In CFD calculation, the continuity equation, momentum conservation equation (also known as the Navier-Stockes transport equations) and energy conservation equation are numerically solved to give the predictions of velocity, temperature, shear, pressure 
profiles, and other parameters such as species concentrations in a fluid flow system. The balance of the conserved variables $\varphi$ such as density, momentum and enthalpy for each phase k, over a fixed domain or element of reactor volume can be expressed by an Eulerian formula as [3]:

$$
\partial \varepsilon_{k} \varphi_{k} / \partial t+\operatorname{div}\left(\varepsilon_{k} u_{k} \varphi_{k}\right)=\operatorname{div}\left(\varepsilon_{k} D_{\varphi_{k}} \operatorname{grad} \varphi_{k}\right)+S_{\varphi_{k}}
$$

where $\varepsilon_{\mathrm{k}}$ is the volume faction of phase $\mathrm{k}, \varphi_{\mathrm{k}}$ is the variable of velocity or temperature to be calculated, $\rho$ is the density of materials, $\vec{u}$ is the velocity vector of flow, $\mathrm{D}$ is the property of materials such as apparent viscosity and thermal conductivity, and $\mathrm{S}$ is the inner generation source such as reaction heat in the energy conservation equation.

The Eulerian-Eulerian, Lagrangian-Eulerian and the volume of fluid multiphase models have been widely used to simulate a multiphase flow. The Eulerian-Eulerian multiphase model considers the different phases as inter-penetrating continua with different phasic volume fractions, $\varepsilon_{\mathrm{k}}$. The Eulerian-Eulerian multiphase model solves the continuity, mass and momentum equations for multiple phases such as fluid and solid phases, tracks the volume fraction of each phase, and then averages the Navier-Stokes equations over the volume fractions. The total phase volume fractions in each computational cell are equal to one [32]. The EulerianEulerian method requires process parameters such as drag, lift, collision, friction forces and heterogeneous chemistry to be included as phase interaction terms in the governing Eq. (25) [32]. The CFD simulation of a multiphase flow is strongly dependent on the proper modeling of the momentum exchange and drag coefficients among phases [33]. The Lagrangian-Eulerian multiphase model treats a fluid phase as a continuum and the particulate phase as single dispersed particles. The basic assumption in this multiphase flow model is that the volume fraction of the dispersed or secondary phase (e.g., solid particle phase) is below 10-12\%, 
although the mass of the secondary phase can be greater than that of the primary phase [32]. The primary phase is treated as continuum by solving the time -averaged Navier-Stokes Eq. (25). The behaviors of particles or the particle trajectories in the particulate phase are obtained by calculating the forces of the primary phase flow field acting on a large number of the particles. The Lagrangian equation used to track particle trajectory is given by [34]:

$$
\begin{aligned}
& m_{p}\left(d u_{p} / d t\right)=(1 / 8) \pi \rho_{p} d^{2} C_{D}\left|u_{f}-u_{p}\right|\left(u_{f}-u_{p}\right)+\left(\pi d^{3} \rho_{f} / 6\right)\left(d u_{f} / d t\right) \\
& +\left(\pi d^{3} \rho_{f} / 12\right)\left(d u_{f} / d t-d u_{p} / d t\right)+\left(\pi d^{3} / 6\right)\left[\left(\rho_{p}-\rho_{f}\right) / \rho_{p}\right] g
\end{aligned}
$$

where $m_{p}$ is the particle mass, $u$ is velocity, $d$ is the diameter of the particle, $\rho$ is density, $g$ is gravity, $C_{D}$ is drag coefficient, and the substitutes of $p$ and $f$ represent particle and fluid. The terms on the right side of the above equation represent the drag, pressure, virtual mass and buoyancy forces, respectively.

Particle trajectories are calculated in the given intervals during the primary flow phase calculations. The volume of a fluid is to track the position of the interface between two or more immiscible fluids [35]. Dispersed and primary phases can exchange mass, energy and momentum [32].

The transport equations of CFD can be applied to both laminar and turbulent flow conditions. The Navier-Stokes Eq. (25) can be solved directly for laminar flows. Turbulent flows are characterized by fluctuating velocity, which affects the heat and mass transfer. However, it is impossible to use the Navier-Stokes equations to simulate the small fluctuations and high frequency of turbulent flows due to the limit of computational capacity. Turbulence modeling is a key issue in CFD simulations. The increase in turbulence can be represented by an increase in 
effective fluid viscosity. The Reynolds-average Navier-Stokes (RANS) model is widely used to determine the effective viscosity by the average and fluctuating components. The large eddy simulation (LES) is typically used to simulate transient effects in turbulent flows. The RANS model is given by [36]:

$\mu_{e f f}=\mu+\mu_{t}$

The eddy viscosity models such as $\kappa-\varepsilon$ approach, and second-order closure models are used to describe the flow turbulence if the effects of turbulence on the effective viscosity need to be considered [36]. There are three widely used turbulence models for CFD modeling of multiphase flows: mixture $\kappa-\varepsilon$, dispersed $\kappa-\varepsilon$ and two-phase $\kappa-\varepsilon$ models. All three turbulence models use the same model constants but have different equations to determine the turbulence viscosity [35].

The most general turbulence model for multiphase flows solves a set of $\kappa$ and $\varepsilon$ transport equations for each phase, which is an appropriate choice when the turbulence transfer among the phases plays a dominant role.

The kinetic energy of turbulence, $\kappa$, can be determined by

$\partial(\rho \kappa) / \partial t+\operatorname{div}(\rho u \kappa)=\operatorname{div}\left[\left(\mu_{e f f} / \sigma_{k}\right) \operatorname{grad} \kappa\right\rfloor+G_{k}-\rho \varepsilon$

The rate of dissipation of the kinetic energy of turbulence, $\varepsilon$, can be determine by

$\partial(\rho \varepsilon) / \partial t+\operatorname{div}(\rho u \varepsilon)=\operatorname{div}\left[\left(\mu_{e f f} / \sigma_{\varepsilon}\right) \operatorname{grad} \varepsilon\right]+C_{\varepsilon 1} G_{k} \varepsilon / \kappa-C_{\varepsilon 3} \rho \varepsilon^{2} / \kappa$

The turbulent viscosity can be determined by

$\mu_{T}=\rho C_{\mu}\left(\kappa^{2} / \varepsilon\right)$

where $\mathrm{C}_{\mu}, \mathrm{C}_{\varepsilon 1}, \mathrm{C}_{\varepsilon 2}$ and $\mathrm{C}_{\varepsilon 3}\left(C_{\varepsilon 3}=C_{\varepsilon 2}+\left[C_{\mu} \rho \eta^{3}(1-\eta) / \eta_{0} /\left(1+\beta \eta^{3}\right)\right]\right)$ are constants of the turbulence model, $\mu_{\text {eff }}$ is the effective viscosity, $\mathrm{G}$ is the generation of the turbulent kinetic 
energy, $\sigma_{\kappa}$ and $\sigma_{\varepsilon}$ are the effective Prandtl numbers for $\kappa$ and $\varepsilon$, respectively. Typical values of these constants are $C_{\mu}=0.09, C_{1 \varepsilon}=1.44, C_{2 \varepsilon}=1.92, \sigma_{k}=1, \sigma_{\varepsilon}=1.3[35]$.

\subsubsection{CFD modeling of thermochemical conversion of biomass in a fluidized bed reactor}

Thermochemical conversion including combustion, pyrolysis and gasification has been used to break down biomass into small gaseous or liquid molecules at an elevated temperature and in the presence or absence of air or oxygen. Fluidized bed reactors have some advantages over fixed bed reactors for thermochemical conversion of biomass including the uniform and controllable temperature distribution in the reactive zone. In a fluidized bed reactor, a gaseous agent such as air, nitrogen or steam is blown upward through the solid bed to fluidize it, enhancing heat and mass transfer and thus thermochemical kinetics [37]. A multiphase reactive flow exists during thermochemical conversion of biomass in a fluidized bed reactor. The biomass reaction occurs at two levels: the particle and the reactor levels [3].

Modeling on the particle level requires the particle size and biomass properties such as density, specific heat and thermal conductivity, which affect the devolatilization rate and dynamic composition of volatiles [21]. Depending on the size of biomass particles, internal or external transport process or both may significantly affect the rate of chemical reactions inside the particles. During the devolatilization of biomass, the biomass particle size is reduced by shrinkage and fragmentation of char. Modeling of the comminution of biomass particles during thermochemical conversion is required to determine the particle size distribution and the average size. The primary fragmentation probability, $\mathrm{P}_{\mathrm{f}}$, can be simply expressed as [38]:

$$
P_{f}=1-\exp \left(-k_{f} t_{v} d_{p}\right)
$$


Modeling on the reactor level requires the reactor design and operating parameters such as biomass feed points and rate. The movement of particles in a reactor depends on the fluid dynamics of the bed. The gas-solid flow of a fluidized bed can be described by mass continuity, momentum and energy conservation equations coupled with the chemical species transport equations presented in a variety of papers [39]. A fluidized bed reactor can be divided into three zones from the bottom to the top: dense bed, splash zone and freeboard. The Eulerian-Eulerian two-fluid model is widely used to study the gas-solid particle flow in the dense bed. In the dense bed, there are three phases: gaseous phase, solid inert bed particulate phase, and solid biomass particulate phase. The solid biomass fuel is generally constitutes $0.5-5 \%$ by mass of the total solids in the bed and the remaining $95-99.5 \%$ solids are a bed material such as sand [32]. Instead of using Eulerian equations (Eq.25) to study the three phases, Papadikis et al. (2008 and 2010) used a combination of Eulerian-Eulerian model and Eulerian-Lagrangian model to study the dense bed $[40,41]$. In this study, the Lagrangian equation (Eq. 27) was used to study the movement of biomass particles, which were introduced to an Eulerian-Euerian bubbling bed of inert san bed. The Eulerian-Lagrangian method by tracking single particle or a particle parcel in a discrete phase can be used the study the gas-solid particle flow in the freeboard zone [32]. However, there are few studies on the application of Eulerian-Eulerian with the consideration of thermochemical reactions in dense bed. No study was reported to simultaneously study both dense bed and freeboard using a CFD model. Also, it is challenging to determine the heat transfer coefficients between biomass and inert bed materials in the dense bed of fluidized bed 
reactor [32].

Biomass gasification involves the transport of many compounds including biomass, tar, char and several gaseous species such as $\mathrm{H}_{2}, \mathrm{CO}, \mathrm{CH}_{4}, \mathrm{CO}_{2}$ and $\mathrm{H}_{2} \mathrm{O}$ and a series of reactions among them. The transport equations for the mass fraction of the $\mathrm{j}^{\text {th }}$ species could be written in a simplified form as follows [39]:

$$
\partial\left(\alpha \rho X_{j}\right) / \partial t+\nabla \cdot\left(\vec{u} \alpha \rho X_{j}\right)=\nabla \cdot\left(\alpha \rho D \nabla X_{j}\right)+R_{j}
$$

where $\rho, \alpha, \vec{u}, D$ and $R_{j}$ are density, volume fraction of a gas phase, flow velocity, diffusion coefficient and the production rate of the $\mathrm{j}^{\text {th }}$ species respectively.

Computational fluid dynamics (CFD) modeling of fluidized bed gasification is a relatively new and promising approach but it requires significant improvements [3]. The mechanical and thermal behavior of reactive gas-solid flows in biomass fluidized bed gasifiers are not well understood due to complex physical and chemical phenomena [21]. The presence of solid particles in the turbulent gas flow in a gravitational field during fluidized bed gasification can lead to a significant reduction of turbulent mixing intensity, which affects the flow mechanical and thermal properties substantially [42]. A high order turbulence closure should be constructed specifically for the turbulent gas flow with solid sediment in the gravitational field. Accurate simulation of microphysical phenomena like particle-particle interaction that causes solid phase pressure gradient and collisional dissipation is another very important part of the mathematical model. Both effects caused by particle-particle interaction seriously affect dynamics of dense gas fluidized beds [43]. 


\subsubsection{CFD modeling of microalgae cultivation systems}

Microalgae can be cultured in open raceway ponds and different types of photobioreactors (PBRs) such as bubble columns, airlift reactors and stirred tank [31]. The success of mass production of microalgae for biodiesel depends greatly on the design and performance of open raceway ponds and photobioreactors. Most algae raceway ponds use channels with constant width and depth, hairpin bends, and one or more paddlewheels to circulate water through the system. This system utilizes sunlight as the main energy source for the photosynthetic reaction to produce biomass and other valuable compounds [44]. Since the performance of mixing in a raceway pond can be determined by the variation of the hydrodynamic properties which are influenced by the geometry of the pond, the investigation of hydrodynamic characteristics and geometry is highly important in the algae pond design to improve mixing, reduce the dead zone and reduce the energy consumption [44]. CFD has been used to investigate hydrodynamic flow properties of algae open ponds and predict algal growth rates [44-46]. The turbulent flow has an important effect on algae growth and therefore needs to be considered on the pond design.

Depending on the type of the algae microorganism, turbulent flow may improve the productivity by enhancing mass transfer and algae cell exposure to the sunlight, decreasing the effect of the photo-inhibition, preventing cell settling and reducing exchange transfer barriers around the cells [45]. Liffman et al. (2013) used a CFD model to investigate fluid speed variation, pressure loss and hydrodynamic power in high rate algal raceway ponds with different raceway bend configurations to minimize the loss of energy that was required to circulate the fluid around the raceway. The new design of the raceway generated by the CFD model could reduce the energy loss by $87 \%$, compared to that of conventional raceway ponds [45]. Hadiyanto et al. (2013) studied the fluid flow, shear stress and the dead zone area in different open raceway pond 
designs using a CFD model. They found that the optimal ratio of length over width of the channels should be at least 10 [44].

In the design of photobioreactors, mixing plays a key role in ensuring light intensity distribution, sufficient $\mathrm{CO}_{2}$ transfer, nutrients distribution, and maintaining uniform $\mathrm{pH}$ and temperature [47]. Mixing is also important to prevent algae sedimentation and avoid the algal cell attachment to the reactor wall. Airlift photobioreactors are a common design for the growth of microalgae. CFD model can be used to track algal cells and generate their trajectories in the reactor. There are two basic methods to model the multiphase flow in a photobioreactor. Eulerian-Eulerian approach treats both the dispersed phase of bubbles and continuous phase of water as interpenetrating continuum. The Eulerian-Lagrangian approach treats the continuous phase using Eulerian equation (Eq. 25) and tracks the dispersed phase by solving the motion equation (Eq. 27) that is based on the balance of all relevant forces on the bubbles or particles such as pressure, gravity, drag, lift and added mass. Luo and Al-Dahhan (2011) developed an Eulerian-Eulerian model (Eq. 25) to simulate the flow dynamics in a draft tube airlift photobioreactor [34]. They used the Lagrangian equation (Eq. 27) to track trajectory of algal particles. The inter-phase momentum transfer between different phases due to interfacial forces in Eq. (25) was expressed as [34]:

$S_{k}=\sum S_{k, i}=S_{k, D}+S_{k, L}+\cdots$

where $S_{k, D}$ and $S_{k, L}$ repsent drag force and lift force. Other minor forces may be also considered.

Drag force which is caused by the movement of bubbles at different velocities to the surrounded liquid phase, which can be determined by the local slip velocity between the continuous and 
dispersed phases as [34]:

$$
S_{k, D}=(3 / 4)\left(C_{D} / d_{b}\right) \varepsilon_{g} \rho_{l}\left(u_{g}-u_{l}\right)\left|u_{g}-u_{l}\right|
$$

where $C_{D}$ is the drag coefficient that can be determined by different correlations [34], $d_{b}$ is the bubble diameter, $\varepsilon_{\mathrm{g}}$ is the volume fraction of gas phase, $\rho$ is density, $\mathrm{u}$ is velocity and the subscripts of 1 and $g$ represent liquid and gas phases.

The lift force is the interfacial forces acting on the direction perpendicular to the major flow direction, which can be determined by [34]:

$$
S_{k, L}=\varepsilon_{g} \rho_{l} C_{L}\left(u_{g}-u_{l}\right) \times\left(\nabla u_{l}\right)
$$

where $\mathrm{C}_{\mathrm{L}}$ is non-dimensional life force coefficient. Other forces such as virtual mass force and turbulence dispersion force may also be considered in a CFD model.

Light penetration is another important parameter that has to be considered carefully to scale up a photobioreactor. Bubble column and airlift photobioreactors are widely used for the growth of microalgae. Local light availability in bubble columns and airlift reactors is affected by aeration rate, gas holdup, and the mixing and turbulence of the liquid medium [48]. The light intensity can be calculated as a function of culture depth, which is given by [49]:

$$
I=I_{0} e^{-\left(k_{x} x+k_{w}\right) z}
$$

where $I_{0}$ is the light intensity at the surface, $\mu \mathrm{E} \mathrm{m}^{-2} \mathrm{~s}^{-1}, \mathrm{k}_{\mathrm{x}}$ is the extinction coefficient for biomass, $\mathrm{ml} \mathrm{m}^{-1}\left(10^{6} \text { cell }\right)^{-1}, \mathrm{x}$ is the biomass concentration, $\left(10^{6}\right.$ cell $) \mathrm{ml}^{-1}, \mathrm{k}_{\mathrm{w}}$ is the extinction coefficient for water, $\mathrm{m}^{-1}$, and $\mathrm{z}$ is the depth, $\mathrm{m}$. 


\subsubsection{CFD modeling of anaerobic digesters and bioreactors}

Anaerobic digestion is a biological process to break down organic materials such as agricultural, food and animal wastes into methane and carbon dioxides by methane-producing bacteria [5056]. Proper mixing is needed for the optimal performance and operation of anaerobic digesters since mixing or agitation is required to homogenize the contents of digesters, ensure uniform distribution of substrate and microorganisms culture, avoid settling of the heavy solid particles to the bottom, avoid the flotation of biomass at the surface of the slurry, and maintain the desired $\mathrm{pH}$ and temperature of the slurry for the microbial processes [50, 54]. Common mixing methods involve the use of gas spargers, mechanical stirring, and mechanical pumping, among which the mechanical stirring has proven to be the most efficient method in terms of mixing intensity per unit power consumption [55].

The flow pattern inside a digester determines the intensity of mixing. Therefore the ability of the digester to be operated at a desired efficiency for a long time depends ultimately on the nature of the flow pattern obtained [50].CFD can be used to provide complete flow patterns of various design scenarios in a short time at a relatively low cost [50-56]. Mechanical mixing of liquid sewage inside an anaerobic digester is very complex, which is governed by continuity, momentum, and turbulence equations in a CFD model. The nature of flow is subject to the physical properties such as viscosity and density of the sludge in a digester [52].

$\mathrm{Wu}$ (2011) investigated the effects of six turbulence models (built into the ANSYS CFD simulation software) for mechanical agitation of non-Newtonian fluids in a lab-scale anaerobic digestion tank with a pitched blade turbine (PBT) impeller [55]. The turbulence models included 
(1) the standard $\kappa-\varepsilon$ model, (2) the RNG $\kappa-\varepsilon$ model, (3) the realizable $\kappa-\varepsilon$ model, (4) the standard $\kappa-\omega$ model, (5) the SST $\kappa-\omega$ model, and (6) the Reynolds stress model. Through comparing power and flow numbers for the PBT impeller obtained from CFD with those from the lab specifications, it was found that the realizable $\kappa-\varepsilon$ and the standard $\kappa-\omega$ models were more appropriate than the other turbulence models for modeling anaerobic digesters [55].

Wastewater sludge is a non-Newtonian fluid and its rheology has significant effect on its flow characteristics [53]. Since a sewage sludge exhibits pseudo-plastic (shear thinning) fluid behavior, it is important to alter the turbulence equation to reflect the dependence of viscosity and density on the shear rate that result from mechanical mixing. A power law was used to determine the viscosity of sewage sludge as a function of shear rate $(\gamma)$, temperature $(\mathrm{T})$ and total dissolved solids (TS) of the sewage sludge, which was given by [53]:

$$
\eta=K \gamma^{n-1} e^{\left(T_{0} / T\right)}
$$

where $\eta$ is the apparent viscosity, $K$ is the consistency index and $n$ is the flow behavior index ( $<<1$ for pseudo-plastic fluids), $\gamma$ is the shear rate that can be calculated linearly from the rotational speed of the impeller $\left(\gamma=k_{s} N\right), \mathrm{T}_{0}$ is the reference temperature and $\mathrm{T}$ is the liquid temperature. Table 6 gives the values of $\mathrm{K}$ and $\mathrm{n}$ as a function of the concentration of total solids in sewage sludge.

$\mathrm{Wu}(2010)$ used the following equation to calculate the density of a waste sludge [49]:

$\rho=0.0367 T S^{3}-2.38 T S^{2}+14.6 T S+1000$ 
A similar CFD technique has also been used to simulate the mixing and hydrodynamic

characteristics of a gas-liquid-solid multiple phase flow in bioreactors to improve their design and operation [57-59].

\subsection{Mathematical Modeling of the Multiple-Scale Flows of Energy and Materials in a}

\section{Biorefinery}

\subsubsection{ASPEN Plus modeling of energy and materials in conversion processes}

The commercial software, ASPEN Plus from AspenTech, Inc., is a widely used simulation platform to analyze the mass and energy balance in a chemical engineering process. ASPEN Plus can be used to develop equilibrium process models. The equilibrium models are important to predict the highest conversion or thermal efficiency that can be possibly obtained by a given process. ASPEN Plus has abundant library models for different unit operations such as reactions, separation and heat exchange. It is also possible for users to develop their own models using FORTRAN codes nested with the ASPEN Plus input file. Another advantage of ASPEN Plus is that it has a large database for the properties of different common chemicals such as water and ethanol. Many key components such as biomass, cellulose, xylan and lignin in a biorefinery are specified as non-conventional components in ASPEN Plus. National Renewable Energy Lab (NREL), USA has defined the properties of those biomass-related components in simulation model. An example is the ultimate and proximate analysis of organic wastes, which is given in Table $7[60]$.

ASPEN Plus simulation can be used to optimize design and operating variables of unit operations of a process such as lignocellulosic ethanol biorefinery [61-65], biomass gasification 
[60,66,67], biomass pyrolysis-based refinery [68] and organosolv biorefinery [69] to analyze and improve the overall efficiency and economics.

\begin{abstract}
ASPEN Plus has been used to simulate a biomass gasification process $[60,66,67]$. The overall gasification process was assumed to consist of four unit operations including decomposition of the feed, volatile reactions, char gasification, and gas-solid separation. The library models with ASPEN Plus including (1) the yield reactor, RYIELD, (2) Gibbs reactor, RGIBBS, (3) CSTR reactor, RCSTR, and (4) CYCLONE in the ASPEN Plus were then selected to simulate the four major unit operations, respectively as shown in Fig. 4.
\end{abstract}

In the yield reactor, RYIELD, the biomass was converted into its constituting components of carbon, hydrogen, oxygen, sulfur, nitrogen, and ash. The yields of the decomposed components were determined according to the biomass ultimate analysis. A SPERATION COLUMN model was then used to separate the char and volatiles exited from the yield reactor. The homogeneous reactions among the volatiles were simulated by the Gibbs equilibrium using the RGIBBS model. The char gasification was simulated by the reaction rate kinetics using the CSTR model. The separation of syngas and char was finally simulated using the CYCLONE model. The simulation results for the product gas composition and carbon conversion efficiency versus temperature, equivalence ratio (ER), steam-to-biomass ratio, and biomass average particle size were well agreed with the experimental results [66].

The ASPEN Plus models could not directly predict the yields of char and tar, and the composition of tar during the biomass gasification, which should be determined by experimental 
data $[60,66,67]$. Zheng et al. (2013) developed an ASPEN Plus model to simulate the biomass integrated gasification combined cycle [67]. In their model, the amount of char produced during biomass gasification was set at $19.7 \%$ of the total carbon entering the gasifier, which was the measured yield of char generated in a similar biomass gasification process. The general chemical formula of tar can be expressed as $\mathrm{C}_{\mathrm{x}} \mathrm{H}_{\mathrm{y}} \mathrm{O}_{\mathrm{z}}$ and the $\mathrm{x}, \mathrm{y}$ and $\mathrm{z}$ values are affected by the properties of biomass feedstock and the gasification conditions, which can be analyzed by experiments. In the model developed by Zheng et al. (2013), the tar was represented by $\mathrm{C}_{6} \mathrm{H}_{6} \mathrm{O}$ while the N, S and $\mathrm{Cl}$ in biomass were assumed to be converted to $\mathrm{NH}_{3}, \mathrm{H}_{2} \mathrm{~S}$ and $\mathrm{HCl}$ during the gasification, respectively.

The APSEN Plus software may not have proper library models to simulate some process units such as ethanol fermentation and adsorption. However, user subroutines can be developed using Microsoft Excel and MatLab to simulate those process units, which can be integrated into the simulation platform of APSEN Plus [64]. ASPEN Plus based process models have been widely integrated with economic models and life cycle models to assess the process economics and environmental impacts $[63,64,67]$. The mass and energy balance through a bioenergy production system can be calculated by the APSEN Plus software. The process simulation results can be used as the inputs of the software of Icarus Process Evaluator developed by AspenTech Inc. to estimate the sizes and the costs of the unit operations [63]. The process simulation results can also be used to supply inventory data for the life cycle assessment of the environmental impacts of a bioenergy system [70,71].

\subsubsection{Metabolic flux analysis of cells}


A metabolic network is an abstract representation of cellular metabolism. Each compound in a biological system may be involved in several biochemical reactions in the cell. For each relevant metabolite, a mass balance can be derived in which both the transport rates over the cell membrane and the intracellular reaction rates are included. The conversion rate of a metabolite in a biological system is a function of the stoichiometry and the metabolic flux through the respective reactions. The net conversion rate of each compound can be generally expressed as $r_{i}=d m_{i} / d t=\left[N_{j, i}\right]^{T} v_{j}$

In the above equation, $\mathrm{N}_{\mathrm{j}, \mathrm{i}}$ is the stoichiometric matrix containing all coefficients of reactions with one row per reaction, $v_{j}$ is the flux vector through reaction $j, r$ is the net formation rates of metabolite $\mathrm{i}, \mathrm{i}$ is the total number of compounds including substrates, products and intracellular metabolites, and $\mathrm{j}$ is the number of fluxes. A set of linear equations (39) give the relationship 
between the mass balances of each metabolite and a set of unknown of fluxes. To find the solution to Eq.39, the number of mass balances (equations) should equal to the number of fluxes to be calculated. However, the number of mass balances is usually smaller than the number of fluxes and the set of linear equations is thus underdetermined. To solve an underdetermined network, either some fluxes have to be experimentally determined or extra constraints have to be added $[73,74]$. The cells can be grown on ${ }^{13} \mathrm{C}$-labeled substrate and the labeling patterns of the specific metabolites can be measured using advanced analytical instruments such as gas chromatography-mass spectrometry (GC-MS) and nuclear magnetic resonance (NMR) spectroscopy [75].

The metabolic pathway of Saccharomyces cerevisiae for ethanol production is well characterized as shown in Fig.5 [76]. By quantifying the intracellular fluxes, it might be possible to (1) understand the biochemistry of the cell at a quantitative level, (2) analyze the nutrient requirements of cells and thus redesign the culture medium, and (3) trace metabolic pathways that limit growth and production for precise genetic modification. The metabolic flux analysis can be used to select better genetic traits for heterologous expression, to express multiple genes at optimal levels, to combine various beneficial traits into single strains, and to ferment mixed sugars for targeted fuels and chemicals.

\section{Computer-Aided Design and Analysis of Bioenergy Supply Logistics}

\subsection{Mathematical Modeling of the Economics of Bioenergy Supply Chains}

The logistics of biomass feedstock supply including harvest, storage and delivery are an integral part of the overall bioenergy supply system. The biomass supply chain consists of multiple 
harvesting, storage, pre-processing and transport options. Mathematical models have been developed to analyze and optimize complex biomass supply systems.

\begin{abstract}
A switchgrass-based bioethanol supply chain is shown in Fig.6. Ten items along the switchgrassbased ethanol supply chain that include land, cultivation, harvest, bale storage, bale transportation, loose chop preprocessing, preprocessed biomass transportation, biomass refinery and ethanol transportation contribute to the total cost of the switchgrass to ethanol supply chain.
\end{abstract} A linear model was developed to determine the total cost of the switchgrass-based bioethanol supply chain, which was given by [77]:

$$
\begin{aligned}
& \theta=\sum_{i=1}^{I} \sum_{j=1}^{3} C_{i} X_{i j}+\sum_{i=1}^{I} \sum_{j=1}^{3} P_{i} X_{i j}+\sum_{i=1}^{I} \sum_{j=1}^{3} H_{i} X_{i j} \\
& +\sum_{i=1}^{I} \sum_{j=1}^{2} \sum_{t=1}^{T} \xi_{j} S_{i j t}+\sum_{i=1}^{I} \sum_{j=1}^{2} \sum_{r=1}^{R} \sum_{t=1}^{T} F_{j i r} D_{i r} V_{i j r t} \\
& +\sum_{i=1}^{I} \sum_{k=1}^{K} \alpha_{i k} D_{i k} V_{i k}+\sum_{k=1}^{K} \sum_{r=1}^{R} \sum_{t=1}^{T} \gamma_{k r} D_{k r} V_{k r t}+\sum_{i=1}^{I} \sum_{k=1}^{K} U_{i} V_{i k}+\sum_{k=1}^{K} W_{k} Y_{k} \\
& +\sum_{r=1}^{R} \sum_{t=1}^{T} N_{r} Z_{r t}+\sum_{r=1}^{R} \sum_{q=1}^{Q} G_{r q} Y_{r q} \\
& +\sum_{e=1}^{E} \sum_{r=1}^{R} \sum_{t=1}^{T} \psi_{r e} D_{r e} Z_{r e t}
\end{aligned}
$$

where

$\psi_{r e}$ : bioethanol transportation cost from biorefinery $\mathrm{r}$ to demand zone $\mathrm{e}$

$\xi_{j}:$ storage cost per unit mass for harvest method $\mathrm{j}$

$\gamma_{k r}:$ transportation cost per unit volume of densitified biomass and unit distance from preprocessing facility $\mathrm{k}$ to biorefinery $\mathrm{r}$ $\alpha_{i k}:$ transportation cost per unit volume of loose biomass and unit distance from supply i to preprocessing facility $\mathrm{k}$ 

$\mathrm{C}_{\mathrm{i}}$ : rental cost per unit area in supply zone $\mathrm{i}$
$\mathrm{C}_{\mathrm{i}}$ : rental cost per unit area in supply zone $\mathrm{i}$
$D_{\mathrm{ik}}$ : distance between supply $\mathrm{i}$ and preprocessing facility $\mathrm{k}$
$\mathrm{D}_{\mathrm{ir}}$ : distance between supply $\mathrm{i}$ and biorefinery $\mathrm{r}$
$\mathrm{D}_{\mathrm{kr}}$ : distance between $\mathrm{k}$ and $\mathrm{r}$
$\mathrm{D}_{\mathrm{re}}$ : distance between biorefinery $\mathrm{r}$ and demand zone e
$F_{\mathrm{jir}}$ : traditional bales transportation cost from $\mathrm{i}$ to $\mathrm{r}$ for bale method $\mathrm{j}$
$\mathrm{G}_{\mathrm{rq}}$ : annualized capital cost of biorefinery with capacity level $\mathrm{q}$ at location $\mathrm{r}$

$\mathrm{H}_{\mathrm{i}}$ : harvest cost per unit area in supply zone $\mathrm{i}$

$\mathrm{N}_{\mathrm{r}}$ : bioethanol production cost per unit volume of ethanol in refinery $r$

$\mathrm{P}_{\mathrm{i}}$ : cultivation cost per unit area in supply zone $\mathrm{i}$

$S_{i j t}$ : amount of biomass stored at supply zone $\mathrm{i}$ by harvest method $\mathrm{j}$ during time period $\mathrm{t}$

$\mathrm{U}_{\mathrm{k}}$ : preprocessing cost per unit volume in facility $\mathrm{k}$

$\mathrm{V}_{\mathrm{ik}}$ : amount of loose chop biomass transported from supply $\mathrm{i}$ to preprocessing facility $\mathrm{k}$

$\mathrm{V}_{\mathrm{jirt}}$ : amount of traditional bales from $\mathrm{i}$ to $\mathrm{r}$ during time period $\mathrm{t}$ for bale method $\mathrm{j}$

$\mathrm{V}_{\mathrm{kr}}$ : amount of densitified biomass transported from $\mathrm{k}$ to $\mathrm{r}$

$\mathrm{W}_{\mathrm{k}}$ : annualized capital cost of preprocessing facility in location $\mathrm{k}$

$\mathrm{X}_{\mathrm{ij}}$ : marginal land area in supply zone $\mathrm{i}$ harvested by method $\mathrm{j}$

$\mathrm{Y}_{\mathrm{k}}$ : number of preprocessing facilities in location $\mathrm{k}$

$\mathrm{Y}_{\mathrm{rq}}$ : number of biorefineries with capacity level $\mathrm{q}$ in $\mathrm{r}$ location

$Z_{\text {ret: }}$ volume of ethanol from $r$ to e during time period $t$

$\mathrm{Z}_{\mathrm{r} t}$ : volume of bioethanol produced in refinery $\mathrm{r}$ during time period $\mathrm{t}$ 
The analysis and optimization of a biomass supply chain starts with the flow chart of the supply chain like the one as shown in Fig.6. The inventory data for the model parameters should be carefully collected and evaluated to ensure the reliability of the analysis and optimization using the model. The simulation using the above model showed that if the biorefineries are not optimally located, the total cost of the switchgrass based bioethanol supply chain in North Dakota in United States could increase by $17 \%$ and the resulting transportation cost could increase by up to $400 \%$ [77].

\begin{abstract}
A bioenergy supply chain can be optimized in terms of total cost, energy use and environmental impact. The integrated biomass supply analysis and logistics (IBSAL) model, which was developed at Oak Ridge National Laboratory, U.S., can be used to estimate the costs, energy use and greenhouse gas emissions for different biomass supply chains [78]. The model has different sub-modules for harvesting, processing, storage and transportation. The input data of the model include local weather data, average yield of biomass, proportion of land for the biomass supply, crop harvesting information, capacity of the biorefinery, dry matter loss in storage, biomass moisture content at the time of harvest, and capital and operating costs of agricultural machinery. The output data of the model include the cost to deliver biomass to a biorefinery, GHG emission, and energy consumption [78]. Kumar and Sokhansanj (2008) found that for the supply of switchgrass at 2000 dry tons/day, the delivered cost for the different supply systems was $\$ 37$ $\$ 48 /$ dry ton. Energy consumption varied from $4.8 \%$ to $6.3 \%$ of the energy content of switchgrass. The emissions varied from 75 to $100 \mathrm{~kg}$ of $\mathrm{CO}_{2} / \mathrm{dry}$ ton of switchgrass delivered. Dry matter loss in the delivery of switchgrass to a biorefinery varied from $3 \%$ to $4 \%$ [78].
\end{abstract}




\subsection{Life Cycle Assessment of Environmental Sustainability of Bioenergy Supply Chains}

Life cycle assessment (LCA) is an emerging tool to measure and compare the environmental impacts of human activities. The LCA has four steps: goal definition and scoping, inventory, impact assessment and interpretation [79]. The impact indicators used in the LCA may include global warming potential, acidification, eutrophication, photochemical oxidation and energy use [80]. Global warming potential is a widely used impact indicator. Carbon dioxide, methane and $\mathrm{N}_{2} \mathrm{O}$ are three gases which contribute to the global warming. Methane has a global warming potential (GWP) 25 times of $\mathrm{CO}_{2}$. $\mathrm{N}_{2} \mathrm{O}$ is another gas which causes global warming. The global warming potential of $\mathrm{N}_{2} \mathrm{O}$ is 310 times of $\mathrm{CO}_{2}$. The global warming score of a system can be determined by [80]:

$$
G W=\sum_{s} G W P_{s} \times m_{s}
$$

where

GW: global warming score

s: substances (the different greenhouse gases such as $\mathrm{CO}_{2}, \mathrm{CH}_{4}$ )

GWP: the global warming potential of the $\mathrm{s}_{\mathrm{th}}$ substance

$\mathrm{m}_{\mathrm{s}}$ : the emitted amount of substance $\mathrm{s}$ in $\mathrm{kg}$

Assumptions may be made to specify the scope of the LCA. It is very important to carefully identify and describe the inputs and outputs for each step and each process involved in the system to be assessed at the inventory step. The data quality strongly affects the reliability of the LCA [81]. LCA has been used to evaluate the environmental impacts of biomass production, bioenergy conversion or the whole bioenergy system [7,82-86]. 
The use of LCA for the biomass production requires the quantification of the regional climate, water availability, nutrient supply and harvesting technology. A life cycle model was used to compare the environmental impacts of microalgae, switchgrass, canola and corn farming [7]. The analysis showed that conventional crops of switchgrass, canola and corn had lower environmental impacts than algae in energy use, greenhouse gas emissions and water consumption although algae had better efficiency of land use and eutrophication potential. The use of flue gas as the source of $\mathrm{CO}_{2}$ and wastewater as a source of fertilizer could significantly reduce the environmental impacts of algal production to make the algae to be competitive as an energy source [7].

The results of life cycle assessment may vary significantly even for similar bioenergy systems due to the differences in type and management of raw materials, conversion technologies, enduse technologies, system boundaries and reference energy system for comparison. Biofuels can contribute to the mitigation of greenhouse gas emissions in the transport sector only if significant emissions from land use change such as soil carbon pools and nitrous oxide emission from soils are avoided and appropriate production technologies are used [6]. It is impossible to give exact values for the amount of greenhouse gas emissions and fossil energy consumption saved by a certain product because many key issues associated with a bioenergy system are site-specific and many factors affect the outcome [6]. However, the LCA can be used to compare the environmental impacts of different biomass production and conversion technology.

\section{Limitation and Challenges in Mathematical Modeling of Biomass}

\section{Production and Biorefineries}




\subsection{Challenges in generalization of bioenergy systems in economic and LCA models}

Bioenergy systems are often very complex in feedstocks, conversion technologies and supply chains. Biomass resources and conversion techniques more often depend on local conditions for biomass feedstock supply and energy uses than fossil fuels. There are large variations in physical and chemical properties of different biomass resources. Biomass fuels are frequently by-products from other main industrial activities such as forestry, agriculture and waste management. Bioenergy supply chains often share costs with other complementary activities by integrating with other industries such as forest industry and food industry for their success. However, mathematical models are always developed by simplifying and generalizing real physical systems. It requires different strategies to predict many unique features of a real bioenergy system compared to the existing fossil-based energy systems [87].

\subsection{Challenges in obtaining physical and chemical properties of biomass}

Mathematical modeling of biomass conversion requires the physical and chemical properties of biomass particles. There are large variations in physical, chemical and structural properties of biomass feedstocks [88-90]. Furthermore, the physical, chemical and structural properties of biomass particles change during conversion. There is very little information about the evolution of chemical composition, physical and structural properties of biomass particles during conversion. Lignocellulosic biomass has three major constituent components of cellulose, hemicelluloses and lignin, and five major elements of $\mathrm{C}, \mathrm{H}, \mathrm{O}, \mathrm{N}$ and $\mathrm{S}$ at different compositions. Those chemical and elemental compositions of biomass can be used to predict its some properties. The biomass calorific values can be predicted from the elemental composition 
of the biomass [90]. It was reported that the thermochemical behavior of biomass can be predicted by the thermochemical behavior of cellulose, hemicelluloses and lignin and their compositions in the biomass [91].

\subsection{Challenges in multi-scale simulation of bioenergy systems \\ The biomass conversion is usually a multi-scale phenomenon. During thermochemical conversion, reactions occur at both solid fuel particle and reactor levels. The individual particles may have different properties and sizes. Each of these particles undergoes a sequence of processes of heating, drying, pyrolysis, combustion or gasification. A particle model can predict the temperature and concentration gradients through a fuel particle. At the reactor level, the chemical species and energy are released from the solid biomass particle bed, and the chemical species further reacts with each other in the gas phase. The simulations at both solid fuel particle and reactor levels should be coupled [92].}

\subsection{Challenges in validation of bioenergy system models}

There are few commercial-scale bioenergy systems in operation, which can provide the firsthand technical and economic data. However, once a mathematical model is developed, the values of a number of parameters have to be obtained as the inputs of the model. The experimental techniques should be available for the determination of the model inputs and the comparison with the predicted results [93].

\section{Conclusions}

Various mathematical models have been developed to predict the growth rate of energy crops 
affected by the environment, the transport phenomena during biomass conversion, the energy and material balances in biomass processing facilities and cells, the conversion reaction kinetics, the biomass supply logistics and the environmental impacts of bioenergy supply. Energy crops such as switchgrass, sweet sorghum and microalgae have been widely investigated. A crop growth model can be used to estimate yields of energy crops in a region under different growth conditions. A GIS model can be used to maximize the energy production of energy crops by indentifying suitable land to grow them based on their specific characteristics and the current use of the land. Biomass can be converted into energy products in various biological and thermochemical processes. Combined multi-scale process models and reaction kinetics provide various advanced computational tools for the design and optimization of the biomass conversion processes. Process simulation can be conducted at a steady state in ASPEN Plus-based equilibrium models. Those equilibrium models assume that chemical equilibrium is reached for process reactions, which can be used to predict the highest conversion or thermal efficiency that can be possibly obtained for a given process. A CFD model can be used to predict transient fluid flow, heat transfer and mass transfer by solving a set of conservation equations. Reaction kinetic models can be used to estimate product formation rates and composition under varying operating conditions, which is essential knowledge for designing and operating a process. Cells are widely used in biological conversion. Metabolic flux analysis can be used to select better genetic traits of cells for heterogonous expression, to express multiple genes at optimal levels, to combine various beneficial traits into single strains, and to ferment mixed sugars for targeted fuels and chemicals. A LCA model can be used to compare the environmental impacts of different biomass production and conversion technologies. The challenges in mathematical modeling of a bioenergy system include the difficulty in generalizing a bioenergy system, the lack of physical 
and chemical properties of various biomass feedstocks, the complexity of multi-scale processes and the validation of the models.

\section{Acknowledgements}

A contribution of North Carolina Agricultural and Technical State University, in fully supported by funds provided by U.S. Department of Energy (DE-EE0003138) and NSF CREST (Award ID 1242152). Mention of a trade name, proprietary products, or company name is for presentation clarity and does not imply endorsement by the authors or the university.

\section{References}

[1] Wang LJ Sustainable Bioenergy Production. Boca Raton, FL: CRC Press; 2014.

[2] van den Broek R, Vleeshouwers L, Hoogwijk M, van Wijk A, Turkenburg W. The energy crop growth model SILVA: description and application to eucalyptus plantations in Nicaragua. Biomass Bioenerg 2001; 21: 335-49.

[3] Gómez-Barea A, Leckner B. Modeling of biomass gasification in fluidized bed. Prog Energ Combust 2010; 36: 444-509.

[4] Zhang Y, Brown TR, Hu G, Brown RC. Techno-economic analysis of monosaccharide production via fast pyrolysis of lignocellulose. Bioresource Technol 2013; 127: 358-65.

[5] Gan J, Smith, CT. Optimal plant size and feedstock supply radius: a modeling approach to minimize bioenergy production costs. Biomass Bioenerg 2011; 35: 3350-9.

[6] Cherubini F, Bird ND, Cowie A, Jungmeier G, Schlamadinger B, Woess-Gallasch S. Energyand greenhouse gas-based LCA of biofuel and bioenergy systems: key issues, ranges and recommendations. Resour Conserv Recy 2009; 53: 434-47. 
[7] Clarens A, Resurreccion EP, White MA, Colosi LM. Environmental life cycle comparison of algae to other bioenergy feedstocks. Environ Sci Technol 2010; 44: 1813-9.

[8] Katterer T, Eckersten H, Andren O, Pettersson R. Winter wheat biomass and nitrogen dynamics under different fertilization and water regimes: application of a crop growth model. Ecol Model 1997; 102: 301-14.

[9] Hein M, Foldager MP, Sand-Jensen K. Size-dependent nitrogen uptake in micro- and macroalgae. Mar Ecol Prog Ser 1995; 118: 247-53.

[10] Concas A, Pisu M, Cao G. Novel simulation model of the solar collector of BIOCOIL photobioreactors for $\mathrm{CO}_{2}$ sequestration with microalgae. Chem Eng J 2010; 157: 297-303.

[11] Packer A, Li Y, Andersen T, Hu Q, Kuang Y, Sommerfeld M. Growth and neutral lipid synthesis in green microalgae: a mathematical model. Bioresource Technol 2011; 102: 111-7.

[12] Gasol CM, Gabarrell X, Rigola M, Gonzalez-Garcia S, Rieradevall J. Environmental assessment: (LCA) and spatial modeling (GIS) of energy crop implementation on local scale. Biomass Bioenerg 2011; 35: 2975-85.

[13] Fiorese G, Guariso G. A GIS-based approach to evaluate biomass potential from energy crops at regional scale. Environ Modell Softw 2010; 25: 702-11.

[14] Mitchell DA, von Meien OF, Krieger N, Dalsenter FDH. A review of recent developments in modeling of microbial growth kinetics and intraparticle phenomena in solid-state fermentation. Biochem Eng J 2004; 17: 15-26.

[15] Wang LJ, Amezquita A, Weller CL. An integrated model of heat transfer and temperaturedependent bacterial growth in cooked hams during air blast chilling. Trans. ASABE 2006; 49(5): 1437-46.

[16] Zajsek K, Gorsek A. Modelling of batch kefir fermentation kinetics for ethanol production 
by mixed natural microflora. Food Bioprod Process 2010; 88: 55-60.

[17] Jin H, Liu R, He Y. Kinetics of batch fermentations for ethanol production with immobilized Saccharomyces cerevisiae growing on sweet sorghum stalk juice. Procedia Environ Sci 2012; 12: 137-45.

[18] Song H, Eom MH, Lee S, Lee J, Cho JH, Seung D. Modeling of batch experimental kinetics and application to fed-batch fermentation of Clostridium tyrobutyricum for enhanced butyric acid production. Biochem Eng J 2010; 53: 71-6.

[19] Zwietering MH, de Koos JT, Hasenack BE, de Wit JC, van't Riet K. Modeling of bacterial growth as a function of temperature. Appl Environ Microb 1991; 57(4): 10940-101.

[20] Luedeking R, Piret EI. A kinetic study of the lactic acid fermentation. Batch process at controlled pH. Biotechnol Bioeng 2000; 67: 636-44.

[21] Di Blasi C. Modeling chemical and physical processes of wood and biomass pyrolysis. Prog Energ Combust 2008; 34: 47-90.

[22] Ahmed TY, Ahmad MM, Yusup S, Inayat A, Khan Z. Mathematical and computational approaches for design of biomass gasification for hydrogen production: a review. Renew Sust Energ Rev 2012; 16: 2304-15.

[23] Lu Q, Zhang Y, Tang Z, Li W, Zhu X. Catalytic upgrading of biomass fast pyrolysis vapors with titania and zioconia/titania based catalysts. Fuel 2010; 89: 2096-103.

[24] Wang Y, Yan L. CFD studies on biomass thermochemical conversion. Int J Mol Sci 2008; 9: 1108-30.

[25] Wurzenberger JC, Wallner S, Raupenstrauch H, Khinast JG. Thermal conversion of biomass: comprehensive reactor and particle modeling. AIChE J 2002; 48: 2398-411. [26] Corella J, Sanz A. Modeling circulating fluidized bed biomass gasifiers. A pseudo-rigorous 
model for stationary state. Fuel Process Technol 2005; 86: 1021-53.

[27] Niksa S. Predicting the rapid devolatilization of diverse forms of biomass with bio-flash chain. Proceeding of $28^{\text {th }}$ International Symposium on Combustion 2000; 8: 2727-33.

[28] Ranzi E, Cuoci A, Faravelli T, Frassoldati A, Migliavacca G, Pierucci S, Sommariva S. Chemical kinetics of biomass pyrolysis. Energy Fuels 2008; 22: 4292-300.

[29] Di Blasi C. Combustion and gasification rates of lignocellulosic chars. Prog Energ Combust 2009; 35: 121-40.

[30] Wu B. Advances in the use of CFD to characterize, design and optimize bioenergy systems. Comput Electron Agr 2013; 93: 195-208.

[31] Bitog JP, Lee IB, Lee GG, Kim KS, Hwang HS, Hong SW, Seo IH, Kwon KS, Mostafa E. Application of computational fluid dynamics for modeling and designing photobioreactors for microalgae production: a review. Comput Electron Agr 2011; 76: 131-47.

[32] Singh RI, Brink A, Hupa M. CFD modeling to study fluidized bed combustion and gasification. Appl Therm Eng 2013; 52: 585-614.

[33] Michele V, Hempel DC. Liquid flow and phase holdup-measurement and CFD modeling for two-and three-phase bubble columns. Chem Eng Sci 2002; 57: 1899-908.

[34] Luo HP, Al-Dahhan MH. Verification and validation of CFD simulations for local flow dynamics in a draft tube airlift bioreactor. Chem Eng Sci 2011; 66: 907-23.

[35] Fluent Co. Fluent Manual. New Hampshire, USA; 2006.

[36] Versteeg HK, Malalsekera W. An Introduction to Computational Fluid Dynamics: the Finite Volume Method. New York: Wiley; 1995.

[37] Basu P. Combustion and Gasification in Fluidized Bed. Boca Raton, FL: CRC Press; 2006.

[38] Nemtsov DA, Zabaniotou A. Mathematical modeling and simulation approaches of 
agricultural residues air gasification in a bubbling fluidized bed reactor. Chem Eng J 2008; 143: 10-31.

[39] Lathouwers D, Bellan J. Modeling of biomass pyrolysis for hydrogen production: the fluidized bed reactor. Proceedings of the 2001 DOE Hydrogen Program Review, NREL/CP$570-30535 ; 2001$.

[40] Papadikis K, Bridgwater AW, Gu S. CFD modeling of the fast pyrolysis of biomass in fluidized bed reactors, part A: Eulerian computation of momentum transport in bubbling fluidized beds. Chem Eng Sci 2008; 63: 4218-27.

[41] Papadikis K, Gu S, Bridgwater AW. A CFD approach on the effect of particle size on char entrainment in bubbling fluidized bed reactors. Biomass Bioenerg 2010; 34: 21-9.

[42] Barenblatt G. Scaling, Self-Similarity, and Intermediate Asymptotics. Cambridge, U.K.: Cambridge Univ. Press; 1996.

[43] Patil DJ, van Sint Annaland M, Kuipers JAM. Critical comparison of hydrodynamic models for gas-solid fluidized beds-Part I: bubbling gas-solid fluidized beds operated with a jet. Chem Eng Sci 2005; 60: 57-72.

[44] Hadiyanto H, Elmore S, Gerven TV, Stankiewicz A. Hydrodynamic evaluations in high rate algae pond (HRAP) design. Chem Eng J 2013; 217: 231-9.

[45] Liffman K, Paterson DA, Liovic P, Bandopadhayay P. Comparing the energy efficiency of different high rate algal raceway pond designs using computational fluid dynamics. Chem Eng Res Des 2013; 91: 221-6.

[46] James S, Boriah V. Modeling algae growth in an open-channel raceway. J Comput Biol 2010; 17: 895-906.

[47] Zhang K, Kurano N, Miyachi S. Optimization aeration by carbon dioxide gas for microalgal 
production and mass transfer characterization in a vertical flat-plate photobioreactor. Bioproc Biosyst Eng 2002; 25: 97-101.

[48] Miron SA, Camacho GF, Gomez CA, Grima EM, Chisti Y. Bubble-column and airlift photobioreactors for algal culture. AIChE J 2000; 46: 1872-87.

[49] Wu X, Merchuk JC. Simulation of algae growth in a bench-scale bubble column reactor. Biotechnol Bioeng 2002; 80: 156-68.

[50] Vesvikar MS, Al-Dahhan M. Flow pattern visualization in a mimic anaerobic digester using CFD. Biotechnol bioeng 2005; 89(6): 719-32.

[51] Wu B. CFD simulation of gas and non-Newtonian fluid two-phase flow in anaerobic digesters. Water Research 2010a; 44(13): 3861-74.

[52] Wu B. CFD simulation of mixing in egg-shaped anaerobic digesters. Water Res 2010b; 44(5): 1507-19.

[53] Bridgeman, J. Computational fluid dynamics modeling of sewage sludge mixing in an anaerobic digester. Adv Eng Softw 2012; 44: 54-62.

[54] Terashima M, Goel R, Komatsu K, Yasui H, Takahashi H, Li YY, Noike T. CFD simulation of mixing in anaerobic digesters. Bioresource Technol 2009; 100(7): 2228-33.

[55] Wu B. CFD investigation of turbulence models for mechanical agitation of non-Newtonian fluids in anaerobic digesters. Water Res 2011; 45(5): 2082-94.

[56] Meroney RN, Colorado PE. CFD simulation of mechanical draft tube mixing in anaerobic digester tanks. Water Res 2009; 43(4):1040-50.

[57] Hristov HV, Mann R, Lossev V, Vlaev SD. A simplified CFD for three-dimensional analysis of fluid mixing, mass transfer and bioreaction in a fermenter equipped with triple novel geometry impellers. Food Bioprod Process 2004; 82(C1): 21-34. 
[58] Wang X, Ding J, Guo W, Ren N. A hydrodynamics-reaction kinetics coupled model for evaluating bioreactors derived from CFD simulation. Bioresource Technol 2010; 101:974957.

[59] Kerdouss F, Bannari A, Proulx P, Bannari R, Skrga M, Labrecque Y. Two-phase mass transfer coefficient prediction in stirred vessel with a CFD model. Comput Chem Eng 2008; 32: $1943-55$.

[60] Ramzan N, Ashraf A, Naveed S, Malik A. Simulation of hybrid biomass gasification using ASPEN PLUS: A comparative performance analysis for food, municipal solid and poultry waste. Biomass Bioenerg 2011; 35: 3962-9.

[61] Aden A, Ruth M, Ibsen K, Jechura J, Neeves K, Sheehan J. et al. Lignocellulosic biomass to ethanol process design and economics utilizing co-current dilute acid prehydrolysis and enzymatic hydrolysis for corn stover. National Renewable Energy Laboratory report no. NREL/TP-510-32438; 2002.

[62] Sassner P, Galbe M, Zacchi G. Techno-economic evaluation of bioethanol production from three different lignocellulosic materials. Biomass Bioenerg 2008; 32: 422-30.

[63] Huang HJ, Ramaswamy S, Al-Dajani W, Tschirner U, Cairncross RA. Effect of biomass species and plant size on cellulosic ethanol: A comparative process and economic analysis. Biomass Bioenerg 2009; 33: 234-46.

[64] Quintero JA, Moncada J, Cardona CA. Techno-economic analysis of bioethanol production from lignocellulosic residues in Colombia: a process simulation approach. Bioresource Technol 2013; 139: 300-7.

[65] Moncada J, El-Halwagi MM, Cardona CA. Techno-economic analysis for a sugarcane biorefinery: Colombian case. Bioresource Technolog 2013; 135: 533-43. 
[66] Nikoo MB, Mahinpey N. Simulation of biomass gasification in fluidized bed reactor using ASPENPLUS. Biomass Bioenerg 2008; 32: 1245-54.

[67] Zheng H, Kaliyan N, Morey RV. Aspen plus simulation of biomass integrated gasification combined cycle systems at corn ethanol plants. Biomass Bioenerg 2013; 56: 197-210.

[68] Ng KS, Sadhukhan J. Process integration and economic analysis of bio-oil platform for the production of methanol and combined heat and power. Biomass Bioenerg 2011; 35: 1153-69.

[69] Garcia A, Alriols MG, Llano-Ponte R, Labidi J. Energy and economic assessment of soda and organosolv biorefinery processes. Biomass Bioenerg 2011; 35: 516-25.

[70] Corti A, Lombardi L. Biomass integrated gasification combined cycle with reduced $\mathrm{CO}_{2}$ emissions: performance analysis and life cycle assessment (LCA). Energ 2004; 29: 2109-24.

[71] Carpentieri M, Corti A, Lombardi L. Life cycle assessment (LCA) of an integrated biomass gasification combined cycle (IBGCC) with $\mathrm{CO}_{2}$ removal. Energ Convers Manage 2005; 46: 1790-808.

[72] Yang YT, Bennett GN, San KY. Metabolic flux analysis of E. coli deficient in the acetate production pathway and expressing the B. subtilis acetolactate synthase. Metab Eng 1998; 1: 26-34.

[73] van Winden WA, van Dam JC, Ras C, Kleijn RJ, Vinke JL, van Gulik WM, Heijnen JJ. Metabolic-flux analysis of Saccharomyces cerevisiae CEN.PK 113-7D based on mass isotopomer measurements of ${ }^{13} \mathrm{C}$-labeled primary metabolites. FEMS Yeast Res 2005; 5: $559-68$.

[74] Cai G, Jin B, Monis P, Saint C. Metabolic flux network and analysis of fermentative hydrogen production. Biotechnol Adv 2011; 29: 375-87

[75] Yang C, Hua Q, Shimizu K. Quantitative analysis of intracellular metabolic fluxes using 
GC-MS and two-dimensional NMR spectroscopy. J Biosci Bioengin 2002; 93: 78-87.

[76] Frabzeb CJ. Metabolic flux analysis of RQ-controlled microaerobic ethanol production by Saccharomyces cerevisiae. Yeast 2003; 20: 117-32.

[77] Zhang J, Osmani A, Awudu I, Gonela V. An integrated optimization model for swithgrassbased bioethanol supply chain. Appl Energ 2013; 102: 1205-17.

[78] Kumar A, Sokhansanj S. Switchgrass (Panicum vigratum, L.) delivery to a biorefinery using integrated biomass supply analysis and logistics (IBSAL) model. Bioresource Technol 2007; 98: $1033-44$

[79] International Standard Organization. Environmental Management - Life Cycle assessment Principles and Framework. International Standard ISO 14040. Geneve: ISO; 1997.

[80] Lundie S, Peters GM. Life cycle assessment of food waste management options. J Clean Prod 2005; 13: 275-86.

[81] Aresta M, Dibenedetto A, Barberio G. Utilization of macro-algae for enhanced CO2 fixation and biofuels production: development of a computing software for and LCA study. Fuel Process Technol 2005; 86: 1679-93.

[82] Collet P, Helias A, Lardon L, Ras M, Goy RA, Steyer JP. Life-cycle assessment of microalgae culture coupled to biogas production. Bioresource Technol 2011; 102: 207-14.

[83] Buonocore E, Franzese PP, Ulgiati S. Assessing the environmental performance and sustainability of bioenergy production in Sweden: a life cycle assessment perspective. Energ 2012; 37: 69-78.

[84] Craig KJ, Nieuwoudt MN, Niemand LJ. CFD simulation of anaerobic digester with variable sewage sludge rheology. Water Res 2013; 47: 4485-97.

[85] Fruergaard T, Astrup T. Optimal utilization of waste-to-energy in an LCA perspective. 
Waste Manage 2011; 31: 572-82.

[86] Khoo HH, Lim TZ, Tan RBH. Food waste conversion options in Singapore: environmental impacts based on an LCA perspective. Sci Total Environ 2010; 408: 1367-73.

[87] Roos A, Rakos C. The limits of modeling. Experiences with bioenergy in practice-could models have predicted this outcome? Biomass Bioenerg 2000; 18: 331-40.

[88] Pecora AAB, Avila I, Lira CS, Cruz G, Crnkovic PM. Prediction of the combustion process in fluidized bed based on physical-chemical properties of biomass particles and their hydrodynamic behaviors. Fuel Process Technol 2014; 124: 188-97.

[89] Wu MR, Schott DL, Lodewijks G. Physical properties of solid biomass. Biomass Bioenerg 2011; 35: 2093-105.

[90] Tao G, Lestander TA, Geladi P, Xiong S. Biomass properties in association with plant species and assortments I: a synthesis based on literature data of energy properties. Renew Sust Energ Rev 2012; 16: 3481-506.

[91] Pang CH, Gaddipatti S, Tucker G, Lester E, Wu T. Relationship between thermal behavior of lignocellulosic components and properties of biomass. Bioresource Technol 2014; 172: 312-20.

[92] Simsek E, Brosch B, Wirtz S, Scherer V, Krull F. Numerical simulation of grate firing systems using a coupled CFD/discrete element method (DEM). Powder Technol 2009; 193: 266-273.

[93] Grace JR, Taghipour F. Verification and validation of CFD models and dynamic similarity for fluidized beds. Powder Technol 2004; 139: 99-110.

[93] Monson CR, Germane GJ, Blackham AU, Smoot LD. Char oxidation at elevated pressures. Combust Flame 1995; 100: 669-83. 
[94] Biggs MJ, Agarwal PK. The $\mathrm{CO} / \mathrm{CO}_{2}$ product ratio for porous char particle within an incipiently fluidized bed: a numerical study. Chem Engin Sci 1997; 52: 941-52.

[95] Muhlen HJ, van Heek KH, Jungen H. Kinetic studies of steam gasification of char in the presence of $\mathrm{H}_{2}, \mathrm{CO}_{2}$ and CO. Fuel 1985; 64:944-9.

[96] De Souza-Santos ML. Comprehensive modeling and simulation of fluidized bed boilers and gasifier. Fuel 1989; 68: 1507-21.

[97] Groppi G, Tronconi E, Forzatti P, Berg M. Mathematical modeling of catalytic combustors fuelled by gasified biomass. Catal Today 2000; 59:151-61.

[98] Wu B, Chen S. CFD simulation of non-Newtonian flow in anaerobic digesters. Biotechnol Bioeng 2008; 99(3):700-11. 


\section{Table titles}

Table 1 input data for the growth of Eucalyptus camaldulensis in Nicaragua [2]

Table 2 Model parameters used for simulation of Spirulina platensis growth [10]

Table 3 Lumped kinetic models for the pyrolysis of cellulose, hemicelluloses and lignin [28]

Table 4 Heterogonous char-gas reactions and kinetics during biomass gasification

Table 5 Homogeneous gas phase reactions and kinetics during biomass gasification

Table 6 Values of $\mathrm{K}$ and $\mathrm{n}$ as functions of concentration of total solids in sewage sludge $[53,98]$

Table 7 Feedstock Condition and their Ultimate and Proximate analysis [60]

\section{Figure captions}

Fig.1. Agroclimate variables and their contribution for the growth of energy crop of Brassica sp. [12].

Fig.2. Kinetic profiles of solid-state fermentation (A. exponential, B. Logistic, C. linear, and D. fast-acceleration/slow-deceleration) [14].

Fig.3. Simplified pyrolysis model [21].

Fig. 4. The diagram of the ASPEN Plus simulation of fluidized bed biomass gasification [66].

Fig.5. Estimated carbon flux distribution in the unit of mmol carbon/C-mol of glucose uptake at $\mathrm{D}=0.25 \mathrm{~h}-1$ and various $\mathrm{RQ}$ (from top to bottom $\mathrm{RQ}=6,12,17,50$ and anaerobic) [76].

Fig.6. A switchgrass based bioethanol supply chain [67]. 


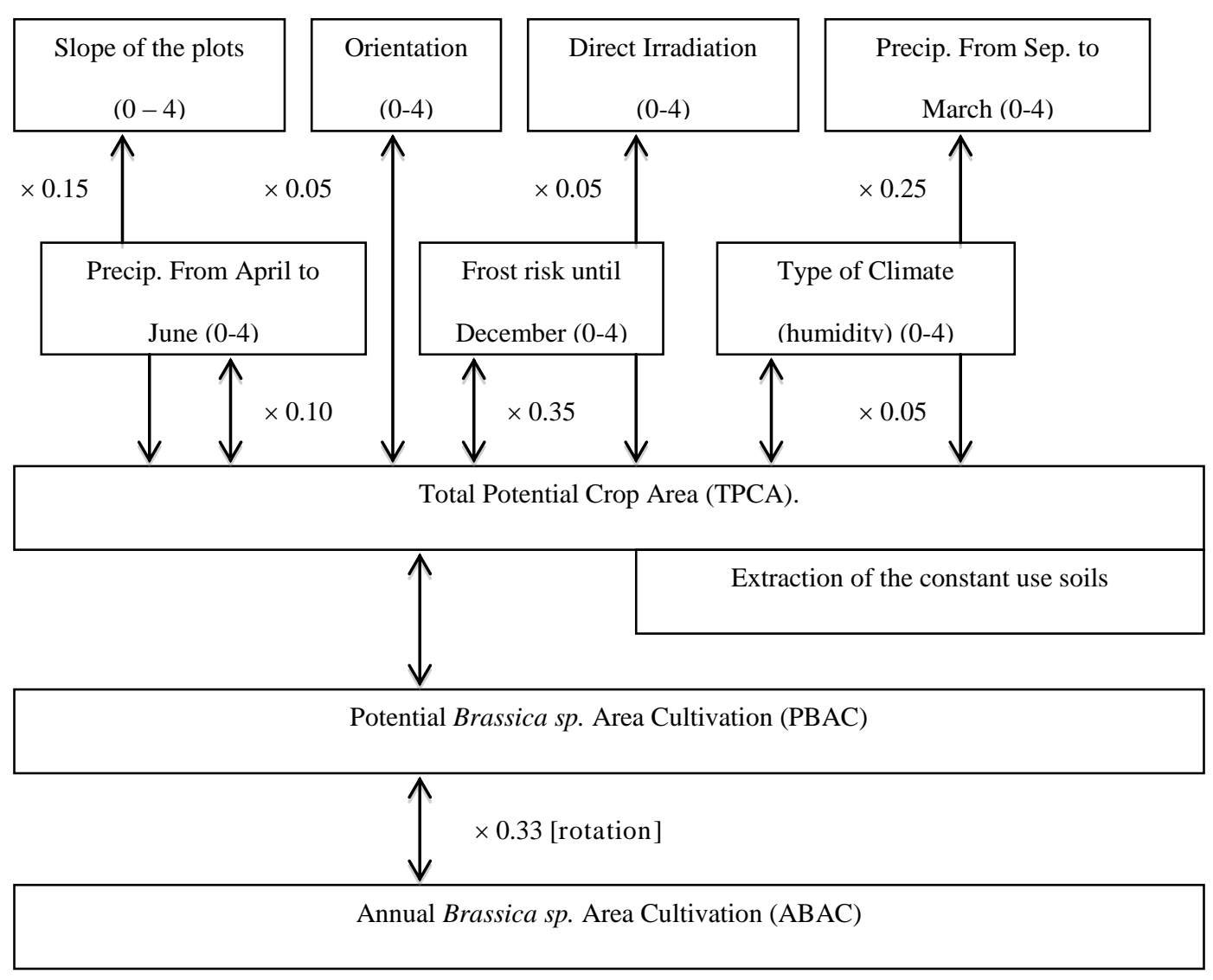

Fig.1. Agroclimate variables and their contribution for the growth of energy crop of Brassica sp. [12]. 


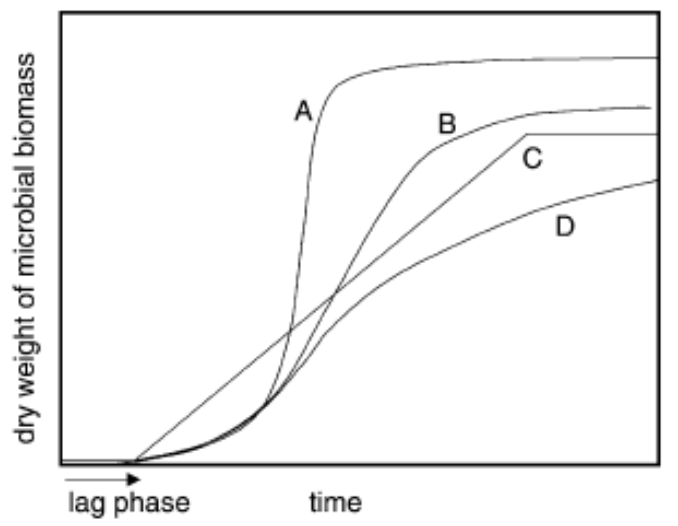

Fig.2. Kinetic profiles of solid-state fermentation (A. exponential, B. Logistic, C. linear, and D. fast-acceleration/slow-deceleration) [14]. 


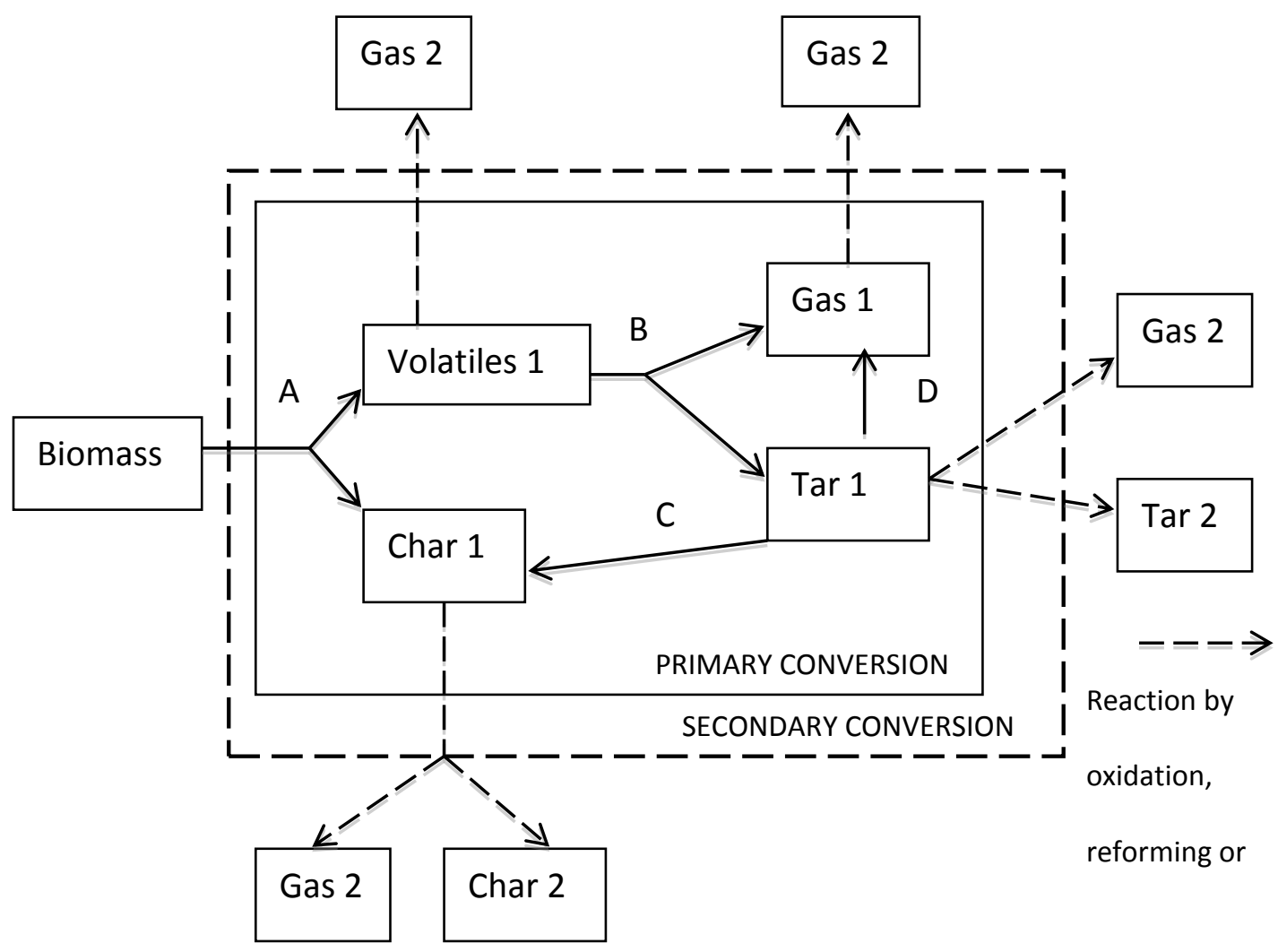

Fig.3. Simplified pyrolysis model [21]. 


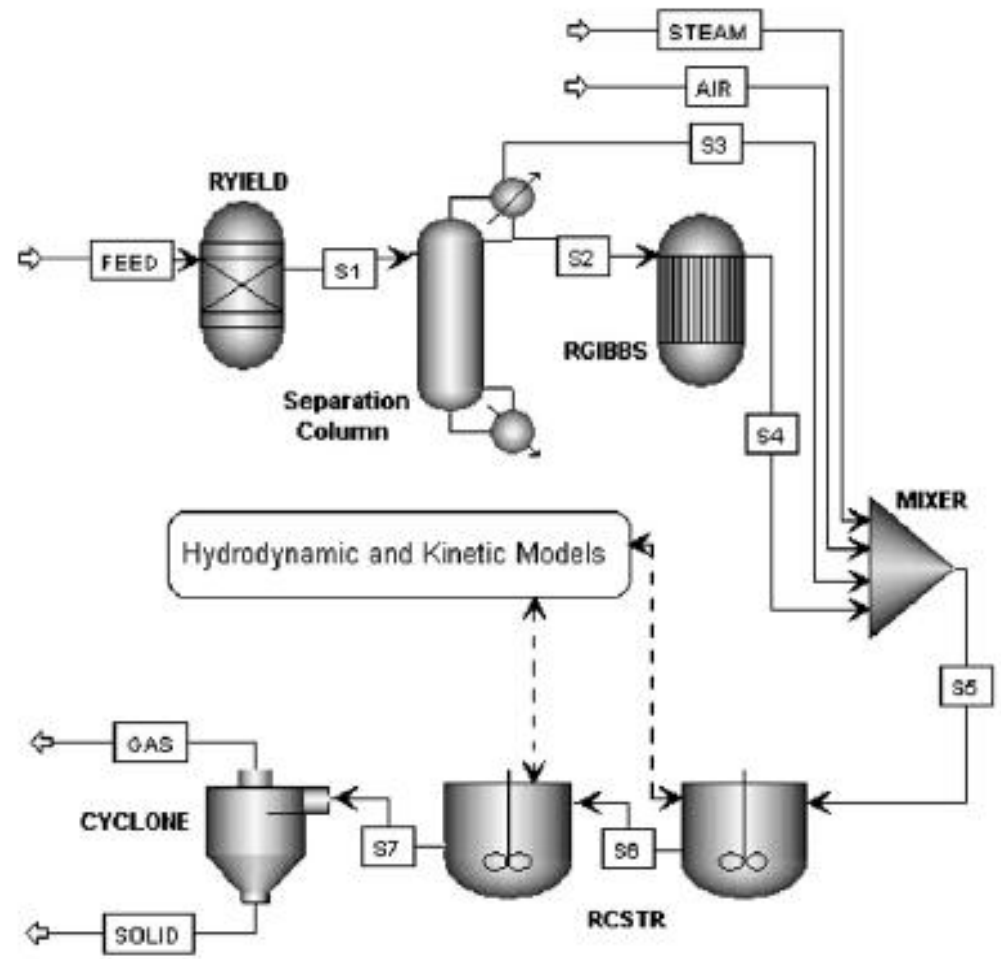

Fig. 4. The diagram of the ASPEN Plus simulation of fluidized bed biomass gasification [66]. 


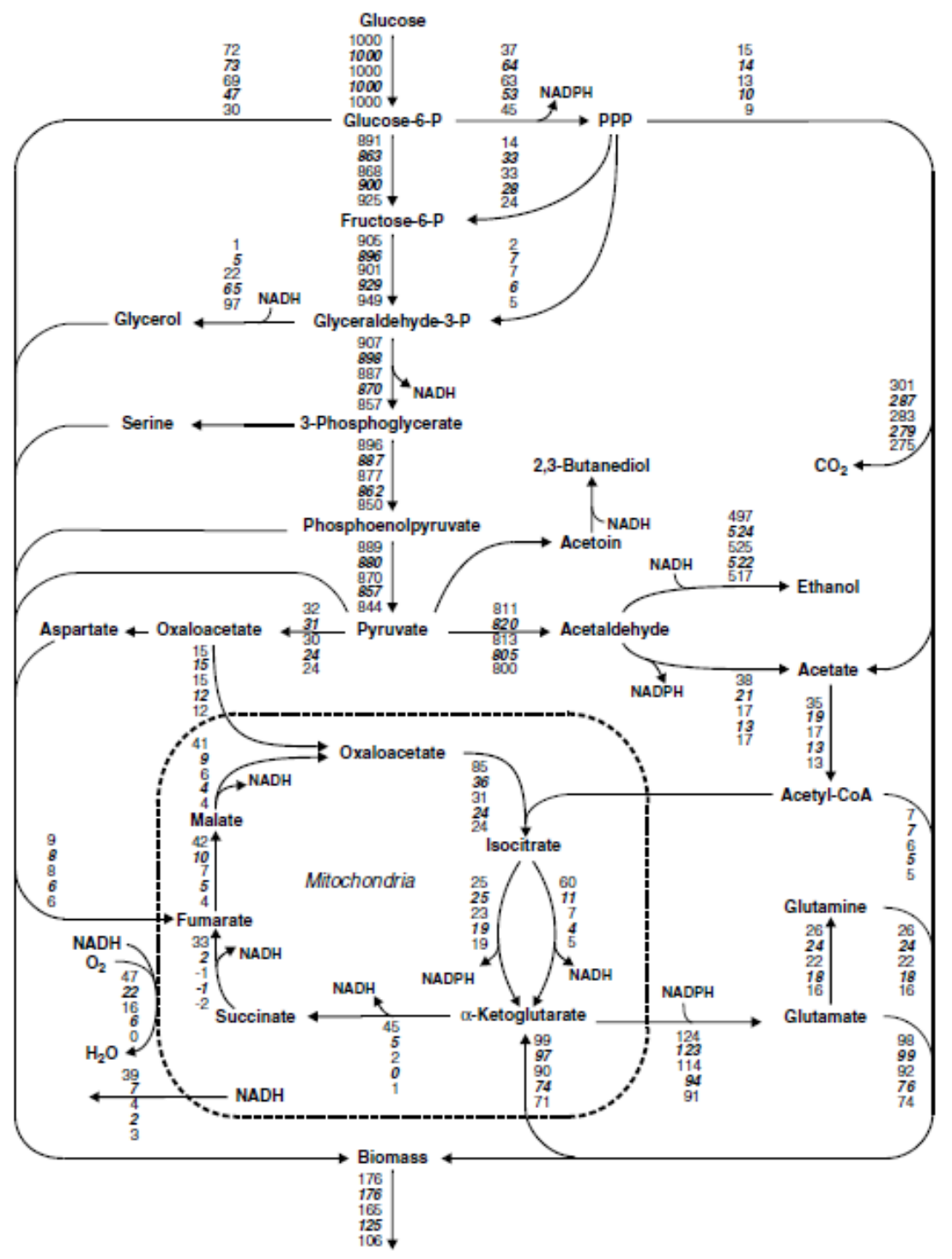

Fig.5. Estimated carbon flux distribution in the unit of mmol carbon/C-mol of glucose uptake at $D=0.25 \mathrm{~h}-1$ and various $R Q$ (from top to bottom $R Q=6,12,17,50$ and anaerobic) [76]. 


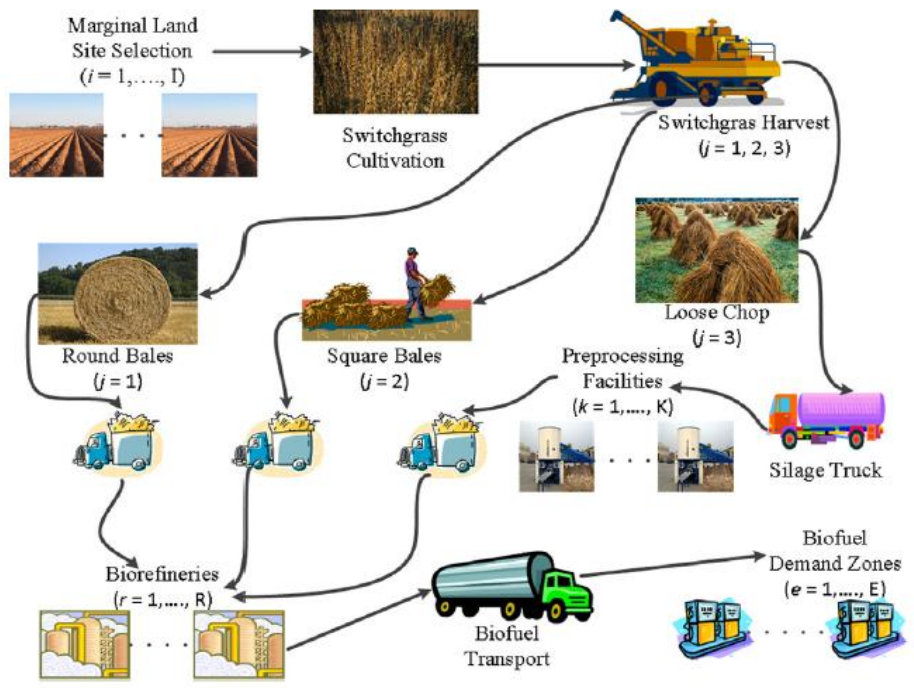

Fig.6. A switchgrass based bioethanol supply chain [67]. 
Table 1 input data for the growth of Eucalyptus camaldulensis in Nicaragua [2]

\begin{tabular}{lll}
\hline Parameter & value & unit \\
\hline$\varepsilon$ & 2.2 & $\mathrm{~g}_{\mathrm{dm}} / \mathrm{MJ}_{\mathrm{PAR}}$ \\
$\mathrm{k}$ & 0.5 & $m_{\text {ground }}^{2} / m_{\text {leaf }}^{2}$ \\
$\varphi$ & 57 & $\mathrm{TJ} /($ ha year $)$ \\
$\mathrm{HI}$ & 0.85 & - \\
LAI & $0.8-3.2^{*}$ & $m_{\text {leaf }}^{2} / m_{\text {ground }}^{2}$ \\
\hline
\end{tabular}

* the leaf area index depends on the growth year and rotation. 
Table 2 Model parameters used for simulation of Spirulina platensis growth [10]

\begin{tabular}{lll}
\hline Parameter & Value & Unit \\
\hline $\mathrm{I}_{\mathrm{K}}$ & 160 & $\mu \mathrm{Em}^{-2} \mathrm{~s}^{-1}$ \\
$\mathrm{~N}$ & 1.49 & - \\
$\mu_{\max }$ & $2.06 \times 10^{-5}$ & $\mathrm{~s}^{-1}$ \\
$\mathrm{~K}_{\mathrm{NO}_{3}}$ & 5.314 & $\mathrm{~g} \mathrm{~m}^{-3}$ \\
$\mathrm{~K}_{\mathrm{H}_{2} \mathrm{PO}_{4}}$ & 0.028 & $\mathrm{~g} \mathrm{~m}^{-3}$ \\
$\mathrm{C}_{\mathrm{O}_{2}, \max }$ & 47.9 & $\mathrm{~g} \mathrm{~m}^{-3}$ \\
$\mu_{\mathrm{c}}$ & 0 & $\mathrm{~s}^{-1}$ \\
\hline
\end{tabular}


Table 3 Lumped kinetic models for the pyrolysis of cellulose, hemicelluloses and lignin [28]

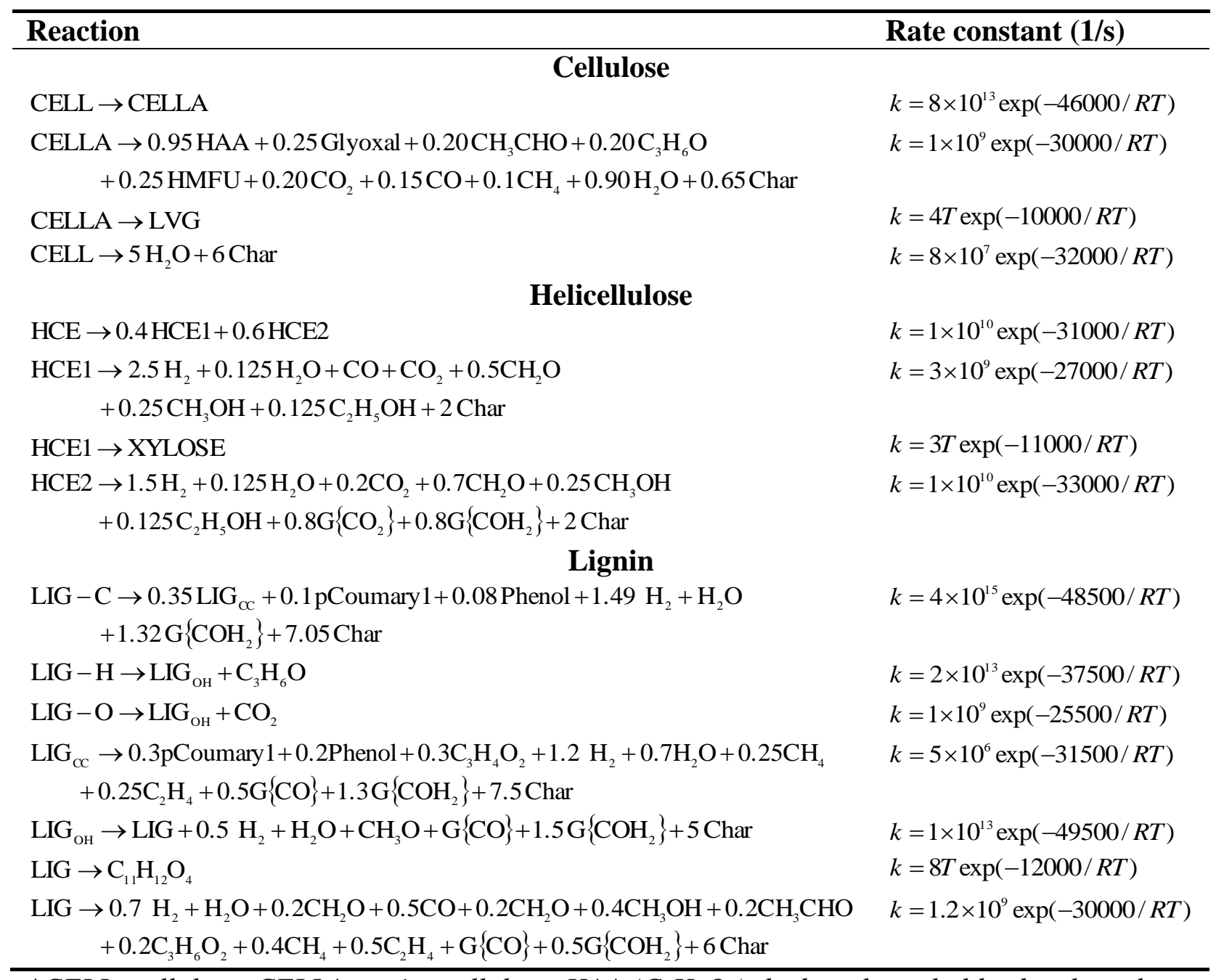

*CELL: cellulose, CELLA: active cellulose, $\mathrm{HAA}\left(\mathrm{C}_{2} \mathrm{H}_{4} \mathrm{O}_{2}\right)$ : hydroxyl-acethaldeyde, glyoxal $\mathrm{C}_{2} \mathrm{H}_{2} \mathrm{O}_{2}, \mathrm{LVG}$ : levoglucosan, $\mathrm{HMFU}$ : 5-hydroxymethyl-furfural, LIG-C: $\mathrm{C}_{15} \mathrm{H}_{14} \mathrm{O}_{4}$, LIG-O: $\mathrm{C}_{16} \mathrm{H}_{10} \mathrm{O}_{6}\left(\mathrm{OCH}_{3}\right)_{4}$ and $\mathrm{LIG}-\mathrm{H}: \mathrm{C}_{17} \mathrm{H}_{13} \mathrm{O}_{4}\left(\mathrm{OCH}_{3}\right)_{5}$ 
Table 4 Heterogonous char-gas reactions and kinetics during biomass gasification

\begin{tabular}{lll}
\hline Reaction & \multicolumn{1}{c}{ Rate } & Reference \\
\hline $2 \frac{\eta+1}{\eta+2} \mathrm{C}+\mathrm{O}_{2} \rightarrow \frac{2 \eta}{\eta+2} \mathrm{CO}+\frac{2}{\eta+2} \mathrm{CO}_{2}$ & $r=1.5 \times 10^{6} \exp (-13078 / T) \cdot p_{\mathrm{O}_{2}} \cdot\left(1-X_{C}\right)^{1.2}(1 / \mathrm{s})$ & {$[29,93]$} \\
$\mathrm{C}+\mathrm{CO}_{2} \rightarrow 2 \mathrm{CO}-172 \mathrm{~kJ} / \mathrm{mol}$ & $r=3 \times 10^{8} \exp (-30178 / T)$ & {$[94]$} \\
$\mathrm{C}+\mathrm{H}_{2} \mathrm{O} \rightarrow \mathrm{CO}+\mathrm{H}_{2}-131 \mathrm{~kJ} / \mathrm{mol}$ & $r=\frac{4.93 \times 10^{3} \exp (-18522 / T) \cdot p_{\mathrm{H}_{2} \mathrm{O}}}{1+1.11 \times 10^{1} \exp (-3548 / T) \cdot p_{\mathrm{H}_{2} \mathrm{O}}+1.53 \times 10^{-9} \exp (25161 / T) \cdot p_{\mathrm{H}_{2}}}$ & {$[95]$} \\
& $(1 / \mathrm{s})$ & \\
\hline
\end{tabular}


Table 5 Homogeneous gas phase reactions and kinetics during biomass gasification

\begin{tabular}{lll}
\hline Homogenous reactions & Rate $\left(\mathbf{m o l} / \mathbf{m}^{3} / \mathbf{s}\right)$ & References \\
\hline $\mathrm{CO}+\mathrm{H}_{2} \mathrm{O} \rightarrow \mathrm{CO}_{2}+\mathrm{H}_{2}+41.1 \mathrm{~kJ} / \mathrm{mol}$ & $\mathrm{r}=2.78 \times 10^{-3} \exp \left(\frac{-1510}{T}\right)\left(c_{C O} c_{\mathrm{H}_{2} \mathrm{O}}-\frac{c_{\mathrm{CO}_{2}} c_{\mathrm{H}_{2}}}{K}\right)$ & [96] \\
$2 \mathrm{CO}+\mathrm{O}_{2} \rightarrow 2 \mathrm{CO}_{2}+566 \mathrm{~kJ} / \mathrm{mol}$ & $\mathrm{r}=3.98 \times 10^{14} \exp \left(\frac{-20119}{T}\right)\left(c_{C O} c_{O_{2}}^{0.25} c_{\mathrm{H}_{2} \mathrm{O}}^{0.5}\right)$ \\
$2 \mathrm{H}_{2}+\mathrm{O}_{2} \rightarrow 2 \mathrm{H}_{2} \mathrm{O}+484 \mathrm{~kJ} / \mathrm{mol}$ & $\mathrm{r}=2.19 \times 10^{12} \exp \left(\frac{-13127}{T}\right)\left(c_{\mathrm{H}_{2}} c_{\mathrm{O}_{2}}\right)$ \\
$\mathrm{CH}_{4}+2 \mathrm{O}_{2} \rightarrow \mathrm{CO}_{2}+2 \mathrm{H}_{2} \mathrm{O}+35.7 \mathrm{~kJ} / \mathrm{mol}$ & $\mathrm{r}=1.58 \times 10^{13} \exp \left(\frac{-24343}{T}\right)\left(c_{C \mathrm{C}_{4}}^{0.7} c_{O_{2}}^{0.8}\right)$
\end{tabular}

*T is the temperature in $K$ and $C$ is the concentration in mole $/ \mathrm{m}^{3}$. 
Table 6 Values of $K$ and $n$ as functions of concentration of total solids in sewage sludge [53, 98]

\begin{tabular}{ccc}
\hline $\mathrm{TS}(\%)$ & $\mathrm{K}^{\left(\mathrm{Pa} \mathrm{S}^{\mathrm{n}}\right)}$ & $\mathrm{n}$ \\
\hline 2.5 & 0.042 & 0.710 \\
5.4 & 0.192 & 0.562 \\
7.5 & 0.525 & 0.533 \\
9.1 & 1.052 & 0.467 \\
12.1 & 5.885 & 0.367 \\
\hline
\end{tabular}


Table 7 Feedstock Condition and their Ultimate and Proximate analysis [60]

\begin{tabular}{llll}
\hline & Food waste & Municipal solid waste & Poultry waste \\
\hline Source & Super market in UK & Municipalities in UK & Local chicken shops \\
& & & \\
\multicolumn{2}{l}{ Proximate analysis (Mass percent) } & & \\
FC & 14.6 & 7.6 & 8.4 \\
VM & 51.1 & 18.8 & 40.3 \\
MC & 29.3 & 50.9 & 7.5 \\
ASH & 4.9 & 22.7 & 43.9 \\
& & & \\
Ultimate analysis (Mass percent) & & \\
ASH & 6.9 & 46.3 & 43.4 \\
C & 56.65 & 36.35 & 22.4 \\
H & 8.76 & 4.96 & 3.8 \\
O & 23.54 & 10.13 & 27.1 \\
N & 3.95 & 1.43 & 2.6 \\
S & 0.19 & 0.83 & 0.7 \\
\hline
\end{tabular}

